Journal for ImmunoTherapy of Cancer

\section{ATM/NEMO signaling modulates the expression of PD-L1 following docetaxel chemotherapy in prostate cancer}

\author{
Zongren Wang, ${ }^{1,2}$ Xueling Zhang, ${ }^{1}$ Wuguo $\mathrm{Li}^{3}{ }^{3}$ Qiao Su, ${ }^{3}$ Zhaoyang Huang, ${ }^{1}$ \\ Xinyao Zhang, ${ }^{1,2}$ Haiqi Chen, ${ }^{1}$ Chengqiang Mo, ${ }^{2}$ Bin Huang, ${ }^{2}$ Wei Ou, ${ }^{2}$ \\ Junxing Chen, ${ }^{2}$ Guangyin Zhao, ${ }^{3}$ Lingwu Chen, ${ }^{2}$ Lan Shao (D) ${ }^{1}$
}

To cite: Wang Z, Zhang $X$, Li W, et al. ATM/NEMO signaling modulates the expression of PD-L1 following docetaxel chemotherapy in prostate cancer. Journal for ImmunoTherapy of Cancer 2021;9:e001758. doi:10.1136/ jitc-2020-001758

\section{- Additional online} supplemental material is published online only. To view, please visit the journal online (http://dx.doi.org/10.1136/jitc2020-001758).

$\mathrm{ZW}, \mathrm{XZ}$ and $\mathrm{WL}$ contributed equally.

Accepted 25 May 2021

Check for updates

(c) Author(s) (or their employer(s)) 2021. Re-use permitted under CC BY-NC. No commercial re-use. See rights and permissions. Published by BMJ.

${ }^{1}$ The Center for Translational Medicine, The First Affiliated Hospital, Sun Yat-sen University, Guangzhou, China

${ }^{2}$ Department of Urology, The First Affiliated Hospital, Sun Yat-sen University, Guangzhou, China

${ }^{3}$ Animal Experiment Center, The First Affiliated Hospital, Sun Yat-sen University, Guangzhou, China

Correspondence to

Dr. Lan Shao;

shaolan@mail.sysu.edu.cn

Dr. Lingwu Chen;

chenlwu@mail.sysu.edu.cn

\section{ABSTRACT}

Background The efficacy of docetaxel-based chemotherapy is limited by the development of drug resistance. Recent studies demonstrated the efficacy of anti-programmed death-1 (PD-1)/programmed cell death ligand-1 (PD-L1) immunotherapies in metastatic prostate cancer. The ataxia telangiectasia mutation (ATM) protein plays a crucial role in maintaining genome stability and function of mitosis. Here, we aimed to determine whether PD-1/PD-L1 signaling contributes to the resistance to DTX and to elucidate the mechanism underlying DTX-induced PD-L1 expression.

Methods In this retrospective study, PD-L1 expression was analyzed in 33 tumor tissue samples from prostate cancer patients. Prostate cell lines were used to perform functional assays and examine underlying mechanisms in vitro. A fully mouse prostate cancer model and a humanized chimeric mouse bearing human prostate tumors and peripheral blood mononuclear cells were used for in vivo assays.

Results We have shown that DTX, a chemotherapeutic drug which causing microtubule interference, could significantly induce the expression of PD-L1 in prostate cancer cells. This effect is blocked by the inhibition of ATM, suggesting that it plays an essential role in PD-L1 expression upregulated by DTX. Mechanistic studies have shown that ATM activity in cancer cells enhances the stability of the NF- $\kappa B$ essential modulator (NEMO), which leading to an increase in the NF- $\kappa B$ activity and PD-L1 expression. Using the mouse model, it was further demonstrated that a combination of ATM and NEMO inhibitors along with DTX augmented the antitumor efficacy of chemotherapy, which are comparable to that of PD-L1 antibody.

Conclusions Our findings have revealed that a previously unrecognized ATM-NEMO signaling which induced by DTX is capable of suppressing tumor immunity by activating the expression of PD-L1, suggesting that the ATM-NEMO-NF$\kappa B$ axis can be exploited to restore the immune balance and overcome cancer resistance triggered by DTX. Graphic Abstract: supplementary file 1

\section{INTRODUCTION}

Programmed death-1 (PD-1) is an important immune checkpoint molecule that mediates immunosuppression by binding to the programmed cell death ligand-1 (PD-L1). High levels of PD-L1 in tumor cells are important for the induction of immunosuppression, immune tolerance, and immune evasion in the tumor microenvironment. ${ }^{1-3}$ Among men, the most common type of invasive cancer is that of the prostate cancer, and it is the second leading cause of death. Recent studies have reported that PD-1 is expressed on the tumor-infiltrating $\mathrm{T}$ cells in patients with prostate cancer and responsible for rapid tumor progression. ${ }^{4-7}$ However, reports on the expression of PD-L1 in prostate cancer cells are conflicting. Although several studies support the involvement of PD-L1 expression and the PD-L1/PD-1 pathway in the progression of prostate tumors, ${ }^{589}$ some reports suggested that PD-L1 is downregulated in prostate cancer. ${ }^{10}$ Therefore, a comprehensive analysis of PD-L1 expression under different medical and therapeutic conditions is necessary for the development of checkpoint inhibitors in prostate cancer.

Docetaxel (DTX)-based chemotherapy is the first-line treatment of metastatic castrateresistant prostate cancer and recent reports also suggest the improving outcomes of DTX in metastatic hormone sensitive prostate cancer. ${ }^{11-13}$ DTX inhibits microtubule depolymerization, thereby activating the M-phase cycle checkpoint. ${ }^{14-17}$ An important issue limiting DTX chemotherapy is the development of drug resistance, which is the primary cause of disease aggravation. ${ }^{18}$ Several studies have reported that anti-PD-1/PD-L1 immunotherapies are effective for the treatment of metastatic prostate cancer (mPCa), ${ }^{15} 19$ suggesting that the PD-1/PD-L1 signaling may contribute to the chemoresistance to DTX.

In this study, we showed that DTX chemotherapeutic treatment upregulated the PD-L1 expression in prostate cancer cells, and identified that ATM-NEMO as the major pathway 
activating PD-L1 expression. Our research provides a new understanding of the mechanism underlying PD-L1 expression in cancer cells, would open a new strategy to overcoming DTX resistance and demonstrates a new way to improve the efficacy of DTX chemotherapy by therapeutically blocking NEMO or ATM signaling.

Ataxia telangiectasia mutation (ATM) is the main kinase that regulates the $\mathrm{G} 2 / \mathrm{M}$ cell cycle checkpoint and activated instinctively in mitosis. ${ }^{20}{ }^{21}$ Recent studies have revealed that DNA damage response (DDR) associated closely with the PD-L1 expression. ${ }^{22-25}$ Nuclear factor kappa-light-chain-enhancer of activated B cells (NF-KB) is a strong inducer of the $P D-L 1$ gene expression in multiple types of cancers. ${ }^{26}$ The activation of NF- $\mathrm{KB}$ in response to multiply cell stresses via an ATM-dependent mechanism. Activated ATM phosphorylates NF-KB essential modulator (NEMO), which results in its modification by SUMOylation and monoubiquitination. Ubiquitinated NEMO is then exported to the cytoplasm, where it phosphorylates IKB kinase- $\beta$ (IKK $\beta$ ) in association with ATM and ELKS (glutamate-rich, leucine-rich, lysine-rich, and serine-rich) proteins, leading to degradation of $\mathrm{I} \kappa \mathrm{B} \alpha$. Thus, p65/RelA is liberated and translocated from the cytoplasm to the cell nucleus. ${ }^{27-29}$ However, whether DTX affects PD-L1 expression and the role of ATM and NF-KB signaling in this process remain to be elucidated.

\section{METHODS \\ Study design}

This study determined whether PD-1/PD-L1 signaling contributes to the resistance to DTX, and elucidated the mechanism underlying DTX-induced PD-L1 expression. PD-L1 expression was analyzed in 33 tumor tissue samples from prostate cancer patients. Prostate cell lines were used to perform functional assays in vitro. Two mouse models with RM-1 and PC-3 bearing prostate tumors were used for in vivo assays. All the surgically resected prostate cancer tissues and peripheral blood mononuclear cells (PBMCs) were obtained from 55 patients at the Department of Urology, the First Affiliated Hospital, Sun Yat-sen University (Guangzhou, China). Table 1 presents the demographic characteristics of 55 patients. The clinical tumor node metastasis (TNM) stage of cancer was assessed by the eighth edition of the American Joint Committee on Cancer (AJCC). The cancer stage was defined according to AJCC prognostic staging system of prostate cancer.

Cell culture and transfection

PC-3, DU-145 and RM-1 prostate cancer cells were obtained from the American Type Culture Collection. The cancer cells were cultured in RPMI 1640 supplemented with 10\% FBS. DTX (MedChemExpress, Monmouth Junction, New Jersey, USA), which promotes microtubule stabilization and inhibits the mitosis of cancer cells; cisplatin (MedChemExpress), a replicative polymerase inhibitor, were used at concentrations of $0,25,50,100 \mathrm{nM}$ and 0 ,
Table 1 Baseline demographics and clinical characteristics

\begin{tabular}{ll}
\hline No of patients & 55 \\
\hline Age, median, years & 66.3 \\
Range, years & $52-80$ \\
Characteristics & No of patients $(\%)$ \\
\hline TPSA $(\mu \mathrm{g} / \mathrm{L})$ & \\
$<4$ & $17(30.9)$ \\
$4-10$ & $15(27.3)$ \\
$10-20$ & $7(12.7)$ \\
$>20$ & $16(29.1)$ \\
FPSA ( $\mu \mathrm{g} / \mathrm{L})$ & \\
\hline $0-1$ & $31(56.4)$ \\
$>1$ & $24(43.6)$ \\
F/T & \\
\hline $0-0.25$ & $44(80.0)$ \\
\hline $0.25-1$ & $9(16.4)$ \\
$>1$ & $2(3.6)$ \\
\hline
\end{tabular}

Gleason sum score

\begin{tabular}{|c|c|}
\hline 6 & $6(10.9)$ \\
\hline 7 & 21 (38.2) \\
\hline 8 & 10 (18.2) \\
\hline 9 & 17 (30.9) \\
\hline 10 & $1(1.82)$ \\
\hline \multicolumn{2}{|c|}{ Disease status } \\
\hline \multicolumn{2}{|c|}{ cT } \\
\hline $\mathrm{T} 1$ & $6(10.9)$ \\
\hline $\mathrm{T} 2 \mathrm{a}$ & $1(1.82)$ \\
\hline $\mathrm{T} 2 \mathrm{~b}$ & 17 (30.9) \\
\hline $\mathrm{T} 2 \mathrm{c}$ & $8(14.5)$ \\
\hline Т3a & 6 (10.9) \\
\hline T3b & 15 (27.3) \\
\hline T4 & 2 (3.64) \\
\hline \multicolumn{2}{|l|}{$\mathrm{N}$} \\
\hline NO & $38(69.1)$ \\
\hline N1 & 17 (30.9) \\
\hline \multicolumn{2}{|l|}{$M$} \\
\hline MO & $39(70.9)$ \\
\hline M1 & $16(29.1)$ \\
\hline \multicolumn{2}{|c|}{ Stage } \\
\hline I & $2(3.64)$ \\
\hline$\| \mathrm{A}$ & $3(5.45)$ \\
\hline IIB & 5 (9.09) \\
\hline IIC & $1(1.82)$ \\
\hline IIIA & 6 (10.9) \\
\hline IIIB & 7 (12.7) \\
\hline IVA & $3(5.45)$ \\
\hline IVB & 28 (50.9) \\
\hline
\end{tabular}

Continued 


\begin{tabular}{ll}
\hline Table 1 Continued & \\
\hline No of patients & 55 \\
\hline Surgical margin status & \\
Positive & $20(36.4)$ \\
Negative & $35(63.6)$ \\
\hline
\end{tabular}

cT, clinical T; FPSA, free prostate-specific antigen; TPSA, total prostate-specific antigen.

10, 20, $30 \mu \mathrm{M}$, respectively. Paclitaxel (PTX, MedChemExpress), was used at concentration of $200 \mathrm{nM}$. Additionally, indicated concentrations of the ATM inhibitor KU55933 (Sigma-Aldrich, St. Louis, Missouri, USA) or the NEMO binding peptide (NBD) (Enzo Biochem, New York, USA) were added at $60 \mathrm{~min}$ before the induction of PD-L1. For inhibitor screening, S3I-201 $(100 \mu \mathrm{M})$, Fludarabine $(10 \mu \mathrm{M})$, UO126-EtOH $(10 \mu \mathrm{M})$, Bayl1-7082 $(10 \mu \mathrm{M})$, JSH-23 $(5 \mu \mathrm{M})$, SD-208 $(2 \mu \mathrm{M})$ which obtained from Sigma-Aldrich were added and the cells were collected after 6 hours.

\section{Flow cytometry}

For extracellular staining, cells were surface stained with FITC-PDL1, PE-PDL1, PE-PDL2, PE-CD8 antibodies (Biolegend, San Diego, California, USA). For intracellular staining, cells were first surface stained with FITC-PDL1, PE-CD8, APC-CD4, PE-CD25, APC-EGFR (Biolegend). In addition, the intracellular staining was performed with a BD permeabilization/Fixation kit. $10^{7}$ cells $/ \mathrm{mL}$ were stained with PE-phospho-ATM, FITC-FOXP3, phospho-p65, and KI67 antibodies (Cell signaling Technology, Danvers, Massachusetts, USA), followed by an Alexa Fluro 488-conjugated Donkey anti-mouse IgG (Jackson ImmunoResearch, West Grove, Pennsylvania, USA), and then detected by LSRII flow cytometer. Data were analyzed by FlowJo software.

For prepared single-cell suspensions from the tumor tissue, The Tumor Dissociation Kit (Mitenyi Biotec, Teterow, Germany) was used.

\section{RNA isolation and quantitative PCR}

Total RNA was extracted from $1.0 \times 10^{5}$ cells, and cDNA was synthesized with AMV-reverse transcriptase and random hexamer primers (Roche Diagnostic, Indianapolis, Indiana, USA). Quantitative PCR (qPCR) was performed using StepOneplus (Applied Biosystems, Carlsbad, California, USA), the gene expression was normalized to GAPDH and the relative amount of mRNA were calculated using the $2^{-\Delta \Delta \mathrm{Ct}}$ method. The primer sequences used for PD-L1: 5'-GGAGATTAGATCCTGAGGAAAACCA-3' and 5'-AACGGAAGATGAATGTCAGTGCTA-3'; GAPDH: 5'CTCCTCTGACTTCAACAGCGA-3' and 5'-CCAAATTC GTTGTCATACCAGGA-3'.

\section{Immunoprecipitation and western blotting}

Cancer cells were lysed in $1.5 \mathrm{~mL}$ of cold lysis buffer. The supernatants of the cell lysates were precleared by protein
A/G PLUS-Agarose, and then incubated with anti-ATM or anti-NEMO with $20 \mu \mathrm{L}$ of protein A/G PLUS-Agarose at $4^{\circ} \mathrm{C}$ for 12 hours. Immune complexes were collected after each immunoprecipitation by centrifugation at $13000 \mathrm{~g}$ for $10 \mathrm{~min}$. The immune complexes were subjected to sodium dodecyl sulfate-polyacrylamide gel electrophoresis (SDS-PAGE), followed by immunoblotting with ATM and NEMO specific antibodies.

Previously reported methods were applied for western blotting. ${ }^{30}$ In brief, whole-cell lysates were prepared in radioimmunoprecipitation buffer. Equal amounts of total protein from each sample were loaded into an SDS-PAGE gel and transferred to a polyvinylidene difluoride membrane. Antibodies specific for PD-L1 (Abcam, Cambridge, Massachusetts, USA), ATM, phospho-ATM, MRE11, p65, phospho-p65 and GAPDH (Santa Cruz Biotechnology, Santa Cruz, California, USA) were added 12 hours at $4^{\circ} \mathrm{C}$. The membranes were subsequently incubated with secondary antibodies and detected with a chemiluminescent detection system (Beyotime Biotechnology, Shanghai, China).

\section{Chromatin immunoprecipitation assay}

Chromatin immunoprecipitation (chIP) assay was preformed to identify the binding site of NF- $\mathrm{KB}$ p 65 in $P D-L 1$ promoter region. PC-3 cells were crosslinked with $1 \%$ formaldehyde at $37^{\circ} \mathrm{C}$ for $10 \mathrm{~min}$, and neutralized with $0.2 \mathrm{M}$ glycine. Then the chromatin was obtained and fractured according to the instructions of chIP assay kit (Beyotime Biotechnology), followed by precipitating with p65 antibody or IgG isotype 12 hours at $4^{\circ} \mathrm{C}$. After purification, the precipitated DNA and input were de-crosslinked at $68^{\circ} \mathrm{C}$. The purified DNA was amplified by PCR and analyzed by $2 \%$ agarose gel, and the capacity of p65 binding to PD-L1 promoter was quantified by qPCR. Primer sequences used in chIP-qPCR were as follows: sense 5'-CTTCCGCAGCCTTAATCCTTA-3' and antisense 5'ATCGTGGATTCTGTGACTTCGTC-3'.

\section{ATM shRNA-mediated knockdown and overexpression}

To knockdown ATM expression, shRNA ATM and control vector were obtained from addgene, $6 \mu \mathrm{g}$ shRNA were transfected into cells by Oligofectamine (Life Technologies, Invitrogen), following protocols provided by the manufacturer. At 24 hours post transfection, cells were treated with $50 \mathrm{nM}$ DTX for 6 hours, and then collected for analysis.

To overexpress ATM plasmids, $2.5 \mu \mathrm{g}$ pcDNA3.1-His and pcDNA3.1-Flag-His-ATM (Addgene) were transfected into tumor cells by Lipofectamine 2000. At 24 hours post transfection, cells were collected for analysis.

\section{Immunofluorescence and immunohistochemistry}

PC-3 cells were cultured in the cell culture chamber. The cells were fixed in $4 \%$ paraformaldehyde for $15 \mathrm{~min}$, permeabilized using $0.2 \%$ triton $\mathrm{X}-100$ for $10 \mathrm{~min}$, followed by staining with rabbit anti-human $\gamma \mathrm{H} 2 \mathrm{AX}$, rabbit anti-human 53BP1, mouse anti-human phospho-histone 
H3, rabbit anti-human phospho-p65 (Cell signal technology) and mouse anti-human PD-L1 antibody (Abcam) or normal control IgG $6-8$ hours at $4^{\circ} \mathrm{C}$. Then, Alexa Flour 488-conjugated goat anti-rabbit IgG and Alexa Flour 594-conjugated goat anti-mouse IgG were added and incubated for 1 hour at $37^{\circ} \mathrm{C}$. The nucleus was stained with 4'6-diamidino-2-phenylindole and mounted with ProLong Gold Antifade Reagent (Life Technologies). The images were analyzed using a Zeiss LSM 880 Confocal Imaging System (Zeiss, Jena, Germany). ${ }^{31}$

Paraffin-embedded tissues were sectioned and subjected to immunostaining using primary antibodies such as anti-PD-L1, anti-CD45, anti-phospho-ATM, antiphospho-p65, anti-CD3 and anti-interferon- $\gamma$ (IFN $\gamma$ ) (Abcam). The isotype-matched primary antibodies served as the controls. Antibody binding was visualized using fluorescence-labeled secondary antibodies under a Zeiss LSM 880 Confocal Imaging System.

\section{Mice and treatments}

The RM-1 cancer models were established by subcutaneously injecting $1 \times 10^{5}$ of RM- 1 cells into the right flank of male C57BL/6 mice (6-8 weeks, GemPharmatech, China). The treatment was initiated once the tumors had reached a size of approximately $90 \mathrm{~mm}^{3}$. For the PC-3 PBMCs engraft mice model, male NOD. CB17-Prkds $c^{\text {sid }} I L 2 \mathrm{rg}^{\mathrm{tm} 1} / \mathrm{Bcgen}$ (B-NDG) mice (5-6 weeks) (Biocytogen Jiangsu, China) were used. PC-3 cells $\left(5 \times 10^{6}\right)$ were injected subcutaneously into the right flank of the mice. The treatment was initiated once the tumors had reached approximately $90 \mathrm{~mm}^{3}$. The mice were treated by an intravenous injection of 10 million PBMCs or CD3depleted PBMCs separated from patients with prostate cancer.

Mice from the same litter were randomly assigned to seven groups as follows: either treated with the vehicle or DTX $(5 \mathrm{mg} / \mathrm{kg})$; DTX $(5 \mathrm{mg} / \mathrm{kg})+\mathrm{KU} 55933(500 \mu \mathrm{g} /$ $\mathrm{kg})$; DTX $(5 \mathrm{mg} / \mathrm{kg})+\mathrm{KU} 55933(500 \mu \mathrm{g} / \mathrm{kg})+$ anti-CD3 $(1 \mathrm{mg} / \mathrm{kg})$; DTX $(5 \mathrm{mg} / \mathrm{kg})+\mathrm{NBD}(100 \mu \mathrm{g} / \mathrm{kg}) ;$ DTX $(5 \mathrm{mg} / \mathrm{kg})+\mathrm{NBD} \quad(100 \mu \mathrm{g} / \mathrm{kg})+$ anti-CD3 $\quad(1 \mathrm{mg} / \mathrm{kg})$ and DTX $(5 \mathrm{mg} / \mathrm{kg})+$ anti-PD-L1 $\quad(1 \mathrm{mg} / \mathrm{kg})$ (clone MIH1; eBioscience, California, USA). The vehicle and KU55933 were delivered every day. Anti-PD-L1, antiCD3, NBD and DTX were delivered every 3, 3, 3 and 4 days, respectively. And an intraperitoneal injection was administered over a period of 14 days. The tumors were measured every 3 days and their volumes were calculated as follows: volume $=\left(\right.$ length $\times$ width $\left.^{2}\right) / 2$. Mean tumor growth inhibition rate was calculated as reported previously. ${ }^{32}$

\section{Statistical analysis}

Data were analyzed using SPSS V.13.0 software, Groups were compared using analysis of variance and unpaired Student's t-test as appropriate. The results were expressed as the mean $\pm \mathrm{SE}$ of the mean. $\mathrm{P}$ values of less than 0.05 were considered significant.
RESULTS

\section{Phosphorylated ATM is correlated with the upregulation of PD-L1 induced by DTX}

$P D-L 1$ expressions in 18 normal and 33 prostate tumor tissues were detected by qPCR (online supplemental table 1 ). As shown in figure $1 \mathrm{~A}$, higher expression of $P D-L 1$ was observed in the prostate tumor tissues compared with that in normal tissues. There is a positive correlation between PD-L1 expression and Gleason score (score $\leq 7$ vs. score $\geq$ $8, \mathrm{p}<0.05)$, lymph node metastasis ( $\mathrm{n}=0$ vs. $\mathrm{n}=1, \mathrm{p}<0.05$ ) and DTX treatment. DTX is the first-line treatment of mPCa. To clarify whether PD-L1 upregulation is due to DTX therapy or metastatic status, we recruited metastatic patients undergoing DTX therapy or not with matched cancer stages and TNM (online supplemental table 2). We found that the $P D-L 1$ expression was significantly higher in patients with metastases who received DTX treatment than in those who did not $(\mathrm{M}=1$, Non vs. DTX, $\mathrm{p}<0.05)$. Furthermore, the $P D-L 1$ expression levels were indistinguishable between patients at M0 or M1 not undergoing DTX treatment $(\mathrm{M}=0$ vs. $\mathrm{M}=1$, no DTX, $\mathrm{p}=$ n.s. $)$. Similar results were observed in patients at different cancer stages (stage IV, Non vs. DTX, $\mathrm{p}<0.05$; stage $\leq$ IIIvs. stage IV, no DTX, $\mathrm{p}=\mathrm{n} . \mathrm{s}$ ), excluding both $\mathrm{M} 1$ and cancer stage as the sole causative factors upregulating PD-L1 expression (figure 1B). Next, we investigated the correlation between PD-L1 expression and ATM kinase activity. The phosphorylated ATM (pATM) and PD-L1 expression was visualized by a dual-color immunostaining in the normal and tumor sections. Elevated levels of pATM with significantly higher PD-L1 expression were only found in the tumor cells, except for CD45 marked tumor-infiltration leukocytes in the tumor sections (figure 1C,D).

To explore the association between PD-L1 upregulation and DTX chemotherapy, we examined the expression of PD-L1 at both gene and protein levels after treatment with DTX. The results showed that DTX upregulated PD-L1 expression in PC-3 (figure 1E) and DU-145 (online supplemental figure 1) prostate cancer cells. Treatment with $100 \mathrm{nM}$ DTX for 6 hours can induced 2.02-fold higher level of $P D-L 1$ than cells which treated with $30 \mu \mathrm{M}$ cisplatin for 24 hours. whereas, the expression of PD-L2 is not upregulated by both treatments (online supplemental figure 2). We further observed that DTX could enhance the ATM enzyme activity in a dose-dependent manner, which was indicated by an increase in the ATM phosphorylation with concomitant increase of total and extracellular PD-L1 expression in prostate cancer cells, as detected by immunoblotting (figure $1 \mathrm{~F}$ ) and fluorescentactivated cell sorting (FACS) staining. A dose of $50 \mathrm{nM}$ DTX can induce an $52.2 \%$ and $100 \mathrm{nM}$ DTX can induce an $86.4 \%$ cells express PD-L1 (figure 1G,H) compared by $55.6 \%$ PD-L1 positive cells from $30 \mu \mathrm{M}$ cisplatin treatment (figure 1I-K). Furthermore, DTX and cisplatin primarily induced PD-L1 accumulation in the cell membrane (online supplemental figure 3). ${ }^{33}$ These data suggested that DTX-induced activation of ATM is associated with the expression of PD-L1 in cancer cells. 

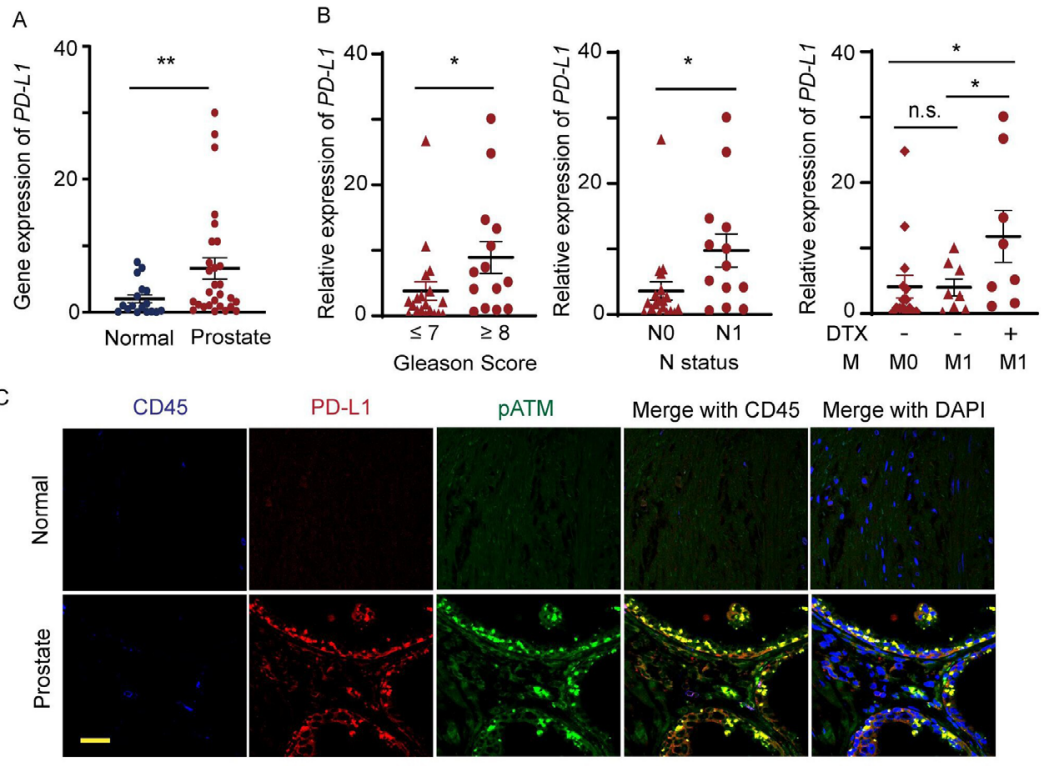

PD-L1

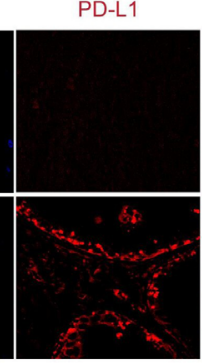

PATM

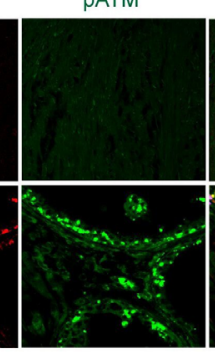

Merge with CD45 Merge with DAPI

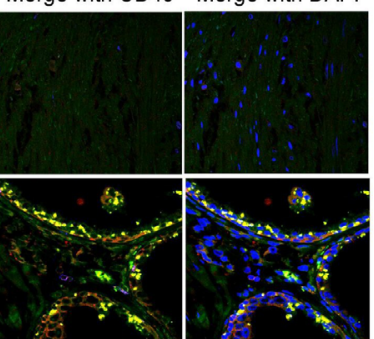

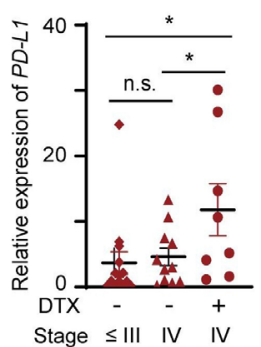

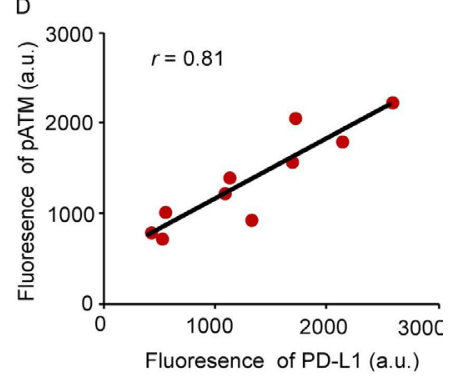

E

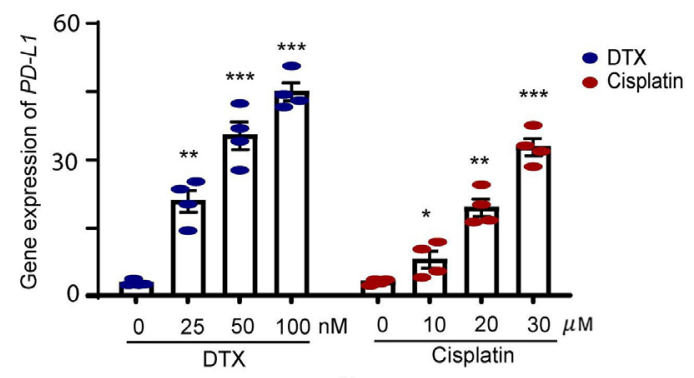

K
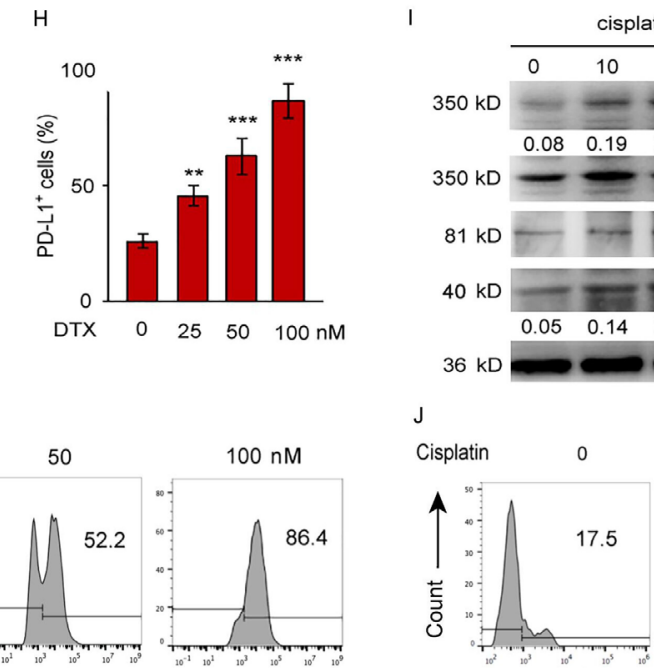

cisplatin

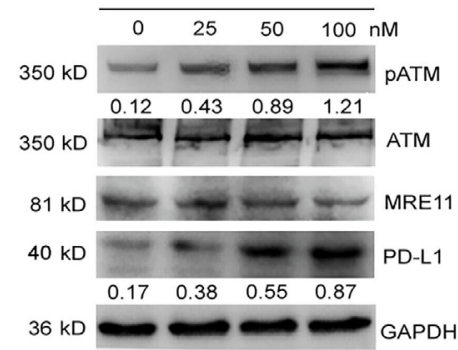

FITC-PD-L1

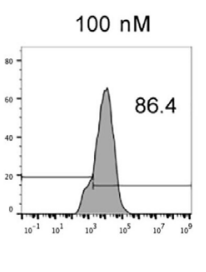

Figure 1 DTX induces PD-L1 expression in patients with prostate cancer. (A-D) Expression of PD-L1 in prostate cancer tissue from prostate cancer patients. (A) $P D-L 1$ gene expression was quantified by qPCR in normal and prostate cancer tissues. The results from 33 patients are represented as scatter plots and bar graphs displaying the mean \pm SEM of the normal and prostate cancer tissues. (B) Relative $P D-L 1$ expression in 33 prostate patients was assessed for correlation with Gleason sum score, TNM status, cancer stage, and docetaxel (DTX) treatment. symbols represent individual subjects; bars show the mean \pm SEM. (C, D) Immunofluorescence staining of PD-L1 (green), pATM (red) and CD45 (blue) in the sections of normal and prostate tumor tissues from 10 patients with prostate cancer. (C) A representation image was shown. (D) Correlation of PD-L1 fluorescence intensity with pATM. (E-K) Cell stresses upregulate PD-L1 expression due to DTX and cisplatin in a dose dependent manner. PC-3 cells were examined at 6 hours after treating with DTX at concentrations of 0, 25, 50, 100 nM; at 24 hours after treating with cisplatin at concentrations of $0,10,20$, and $30 \mu \mathrm{M}$. (E) $P D-L 1$ gene expression after DTX and cisplatin treatment was quantified by qPCR. Results from four experiments. (F-H) DTX treatment. (F) Representative blotting for ATM activation, MRE11 and PDL1 expression after DTX treatment. results from four experiments. (G, H) PD-L1 expression was detected by surface staining with FITC-PD-L1 antibody with isotype IgG as a control. Representative FACS results from four experiments are shown in (G) and with quantifications in $(\mathrm{H})$. (I-K) Cisplatin treatment. (I) Representative blotting for ATM activation and PD-L1 expression after cisplatin treatment. Results from three experiments. (J, K) PD-L1 expression was detected by FITC-PD-L1 antibody with isotype IgG as a control. Representative FACS results from three experiments are shown in (J) and with quantifications in (K). All data are shown as mean \pm SEM. ${ }^{\star} \mathrm{P}<0.05 ;{ }^{\star \star} \mathrm{p}<0.01 ;{ }^{* \star *} \mathrm{p}<0.001$. ATM, ataxia telangiectasia mutation; FACS, fluorescent-activated cell sorting; n.s, not significant; PD-L1, programmed cell death ligand-1; pATM, phosphorylated ATM; qPCR, quantitative PCR; SEM, SE of the mean.

\section{ATM kinase activity regulates PD-L1 expression}

We conducted knockdown experiments to provide further evidences that the expression of PD-L1 was ATM dependent. Transfection of PC-3 cells with ATM-specific silencing RNA significantly reduced the transcription and protein expression of ATM (figure 2A,B). Concomitantly, 


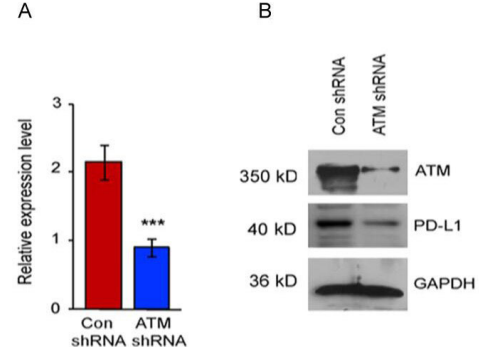

G

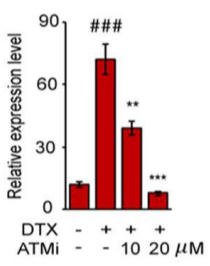

H
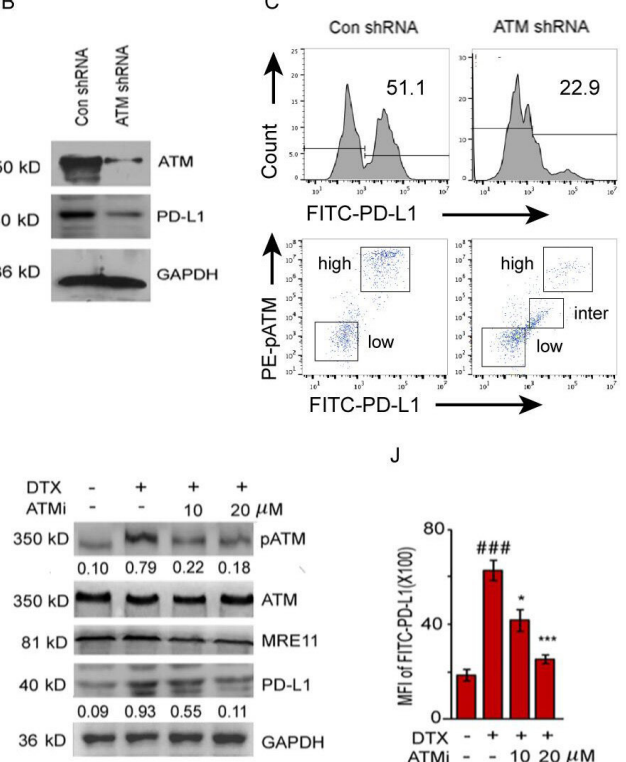

D

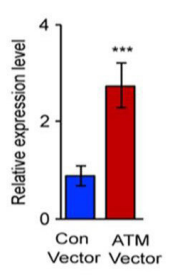

K

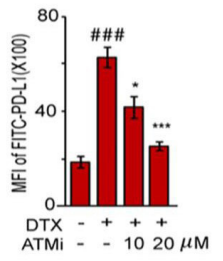

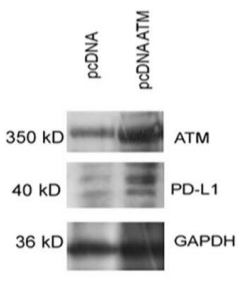

F

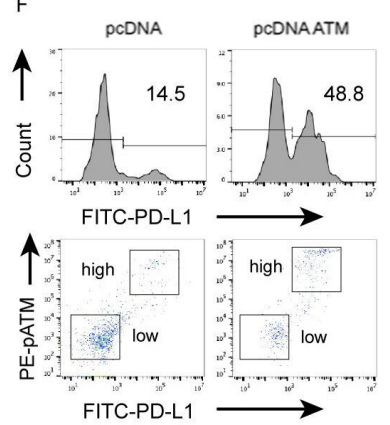

N

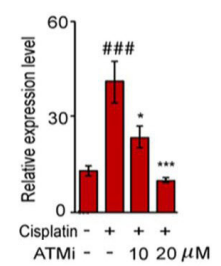

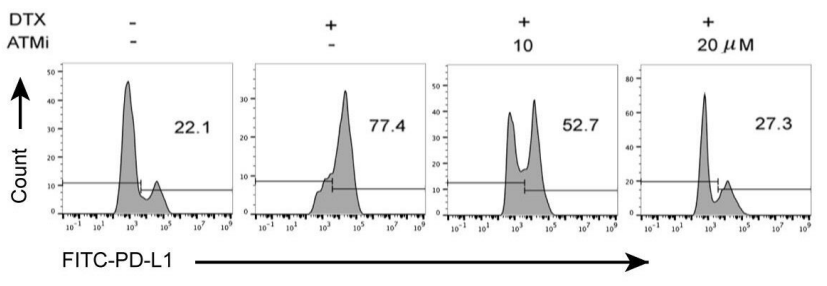
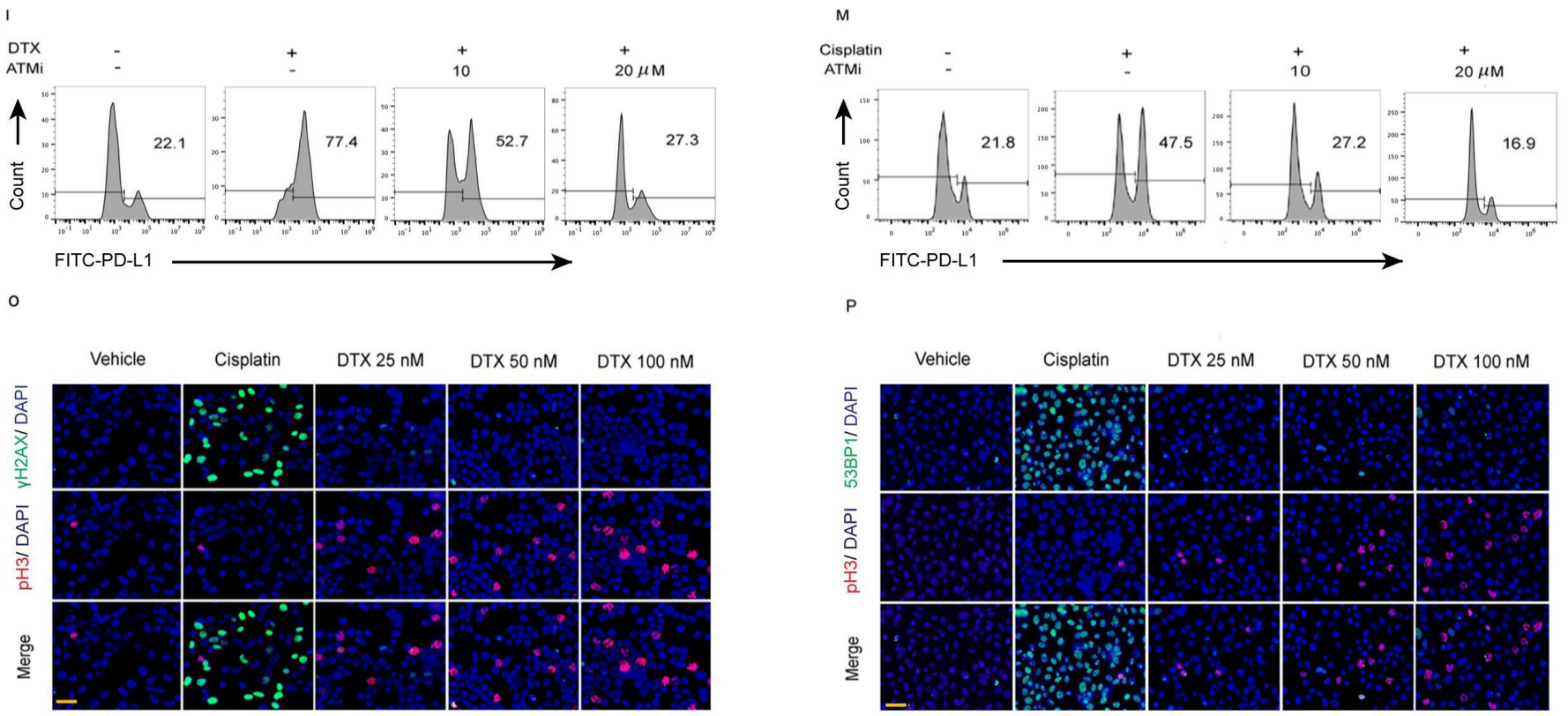

Figure 2 ATM regulates PD-L1 expression induced by DTX. (A-C) PC-3 cells were exposed to ATM shRNA. Forty-eight hours later, the cells were treated with $50 \mathrm{nM}$ DTX for 6 hours and then collected. (A) Knockdown efficiency was detected by qPCR. (B) ATM and PD-L1 expression was determined by Western blotting. (C) The effect of ATM knockdown on the PD-L1 expression was detected by FACS. (D-F) PC-3 cells were transfected with the control and ATM plasmid without DTX treatment. Fortyeight hours later, the cells were collected. (D) Transfection efficiency was detected by qPCR. (E) PD-L1 expression was detected by Western blotting. (F) The effect of ATM transfection on PD-L1 expression was detected by FACS. (G-J) ATM inhibitor (KU55933) can block the PD-L1 expression induced by DTX. PC-3 cells were treated with 50 nM DTX following treatment with the KU55933. (G) PD-L1 gene expression was quantified by qPCR. (H) ATM, pATM, MRE11 and PD-L1 expression was determined by Western blotting. (I, J) PD-L1 expression was detected by FACS. (K-N) ATM inhibitor blocks the PD-L1 expression induced by cisplatin. PC-3 cells were treated with $20 \mu \mathrm{M}$ cisplatin following treatment with the KU55933. (K) PDL1 gene expression was quantified by qPCR. (L) ATM, pATM and PD-L1 expression was determined by Western blotting. (M, N) PD-L1 expression was detected by FACS. (O, P) DTX induces PD-L1 expression is DDR independent. PC-3 cells were examined after treating with DTX and cisplatin. (O) Co-immunostaining of $\gamma \mathrm{H} 2 \mathrm{AX}$ (green) and phospho-histone $\mathrm{H} 3$ (red) in the PC-3 cells. Scale bar, $20 \mu \mathrm{m}$. (P) Co-immunostaining of 53BP1 (green) and phospho-histone H3 (red). Scale bar, $20 \mu \mathrm{m}$. All data are shown as mean \pm SEM. \#\#\#P<0.001, compared with non-treated group; ${ }^{*} \mathrm{p}<0.05,{ }^{* *} \mathrm{p}<0.01,{ }^{* *} \mathrm{p}<0.001$, compared with chemotherapy treated group. ATM, ataxia telangiectasia mutation; DTX, docetaxel; FACS, fluorescent-activated cell sorting; PDL1, programmed cell death ligand-1; pATM, phosphorylated ATM; qPCR, quantitative PCR; SEM, SE of the mean. 
ATM knockdown markedly reduced the protein concentration of PD-L1 (figure 2B). To link increased PD-L1 expression with the activation of ATM kinase activity, extracellular PD-L1 and intracellular pATM expression levels were compared by FACS in individual cells (figure 2C). We subsequently found that the higher the mean fluorescence intensity (MFI) of pATM, the more intense the expression of PD-L1 in the cell membrane.

To test the hypothesis that ectopic activation of ATM could upregulate PD-L1 expression, His-Flag-ATM or control constructs were transfected into PC-3 cells. It was observed that the PD-L1 protein levels had substantially increased in the cells transfected with ATM plasmid (figure 2D-F), indicating that ATM kinase activation is required for DTX-induced PD-L1 expression.

To further investigate whether the PD-L1 expression is associated with ATM activation under DTX chemotherapy, cancer cells were treated with DTX in combination with different doses of the ATM inhibitor. Cisplatin, which activates ATM through DDR signaling, was used as a positive control (figure $2 \mathrm{G}-\mathrm{N}$ ). Inhibition of the enzymatic activity of ATM attenuated the DTX-induced upregulation of PD-L1 expression (figure 2G-J), as well as cisplatin-induced PD-L1 expression (figure 2K-N). Treatment with $20 \mu \mathrm{M}$ of KU55933 was sufficient to suppress PD-L1 expression to the level observed in the untreated cells. Taken together, these results suggested that the activation of ATM kinase was directly responsible for the enhanced expression of PD-L1 in cancer cells after treatment with DTX.

\section{DTX-induced PD-L1 expression is not dependent on DDR activated G2/M checkpoint}

Several proteins involved in DNA damage signaling such as $\gamma \mathrm{H} 2 \mathrm{AX}$ and 53BP1 produce discrete DNA damage foci. ${ }^{34}$ To further compare the mechanisms of DTX and cisplatin-induced PD-L1 expression, the expressions of $\gamma \mathrm{H} 2 \mathrm{AX}$ and 53BP1 after DTX and cisplatin treatment were checked. Accumulation of DNA breaks was confirmed by immunostaining for $\gamma \mathrm{H} 2 \mathrm{AX}$ and 53BP1 in the nuclei of cisplatin treated cells. However, $\gamma \mathrm{H} 2 \mathrm{AX}$ and 53BP1 foci in the nuclei of DTX treated cells were not significantly higher (figure 2O,P). Moreover, ATM undergoes dimer dissociation in response to DSBs. ${ }^{35}$ No significant dimer/ monomer transmission was observed after DTX treatment (online supplemental figure 4), suggesting that DTXinduced ATM activation might not show DDR response. DTX-induced cell accumulation in G2/M phase was indicated by phospho-histone $\mathrm{H} 3$ staining (figure 2O,P) and cell cycle analysis via propidium iodide (online supplemental figure 5). However, there were no distinct $\gamma \mathrm{H} 2 \mathrm{AX}$ and 53BP1 signals in both phospho-H3 positive and negative cells after DTX treatment (figure 2O,P). Generally, ATM functions upstream of ATR in DDR-induced G2/M checkpoint arrest. ${ }^{36}$ To further confirm DTX-induced ATM activation being DDR-induced G2/M checkpoint independent, PC-3 cells were treated with ATR inhibitor following DTX or cisplatin. ATR inhibitor effectively suppressed cisplatin but not DTX-induced PD-L1 expression, suggesting DTX-induced ATM and PD-L1 activation is not trigged by DDR-induced G2/M checkpoint (online supplemental figure 6). To further verify the association of observed responses with the interruption in microtubule, PTX, a microtubule inhibitor, was added to PC-3 cells with the reported treatment which did not induce DNA damage. ${ }^{37}$ PTX activated ATM signal and PD-L1 expression was similar to DTX, which confirmed that disruption of microtubule-induced ATM-dependent PD-L1 expression (online supplemental figure 7).

\section{PD-L1 upregulation is mediated via the NF-KB pathway}

To elucidate the mechanism underlying PD-L1 activation by DTX, a panel of signal pathway inhibitors (STAT3i: S3I-201; STAT1i: Fludarabine; MEK1/2i: UO126-EtOH; Bay11-7082: TNFo-induced NF-KBi; JSH-23: NF-אBi for p65 nuclear translocation; TGF- $\beta$ RIi: SD-208; ATMi: KU55933) were screened to identify the exact pathways regulating the transcription of PD-L1. DTX-induced PD-L1 upregulation in cancer cells was substantially suppressed by JSH-23, which normalized the PD-L1 expression as effectively as ATM inhibitor (figure $3 \mathrm{~A}, \mathrm{~B}$ ), indicating that p65-dependent NF- $\mathrm{kB}$ activation was involved in the modulation of PD-L1 expression.

Further, we confirmed the link between the induction of the ATM activity, PD-L1 expression and increased activation of NF- $\mathrm{KB}$ signaling in the cancer cells after DTX or cisplatin treatment (figure $3 \mathrm{C}-\mathrm{J}$ ). The activity of ATM kinase induced by both treatments was inhibited by KU55933 in tumor cells. Moreover, we observed increased phosphorylation of the NF-kB subunit p65 in the cancer cells treated with either DTX (figure 3C,D) or cisplatin (figure $3 \mathrm{E}, \mathrm{F}$ ). The results of a dose dependent experiment indicated that the inhibition of ATM activity was accompanied by a marked loss of the NF-KB activity and followed by a reduction in the PD-L1 expression . In addition, we further performed chIP assays in DTX treated PC-3 cells with and without ATM inhibitor. Increased p65 bindings to the $P D-L 1$ promotor were observed in response to DTX or cisplatin, and the ATM inhibitor effectively blocked the binding of p65 to the $P D$ L1 promoter (figure $3 \mathrm{G}-\mathrm{J}$ ), suggesting that NF- $\mathrm{KB}$ p65 acts downstream of the ATM to block PD-L1 expression on both DTX and cisplatin chemotherapy.

\section{NEMO is required for PD-L1 upregulation induced by DTX}

Multiple cell stress can activate ATM, which phosphorylates NEMO and enhances its SUMOylation. This step is necessary for the p65 nuclear translocation and NF-KB activation. ${ }^{38-40} \mathrm{NBD}$ is a cell-permeable synthetic peptide capable of selectively inhibiting the activation of NF-KB by disrupting the formation of NEMO and the IKK $\beta$ complex, thus, decreasing the NF-KB p65 dependent gene expression by inhibiting its nuclear translocation.

To determine whether ATM activated NF- $\mathrm{\kappa B}$ and upregulated PD-L1 expression through NEMO, PC-3 cells were treated with the NBD followed by a treatment with either 
A

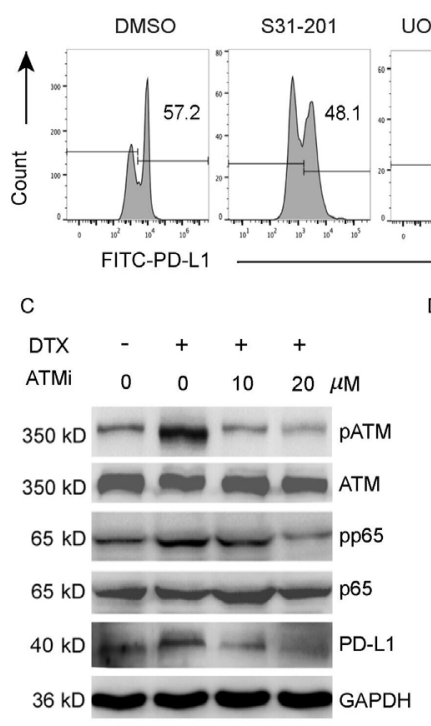

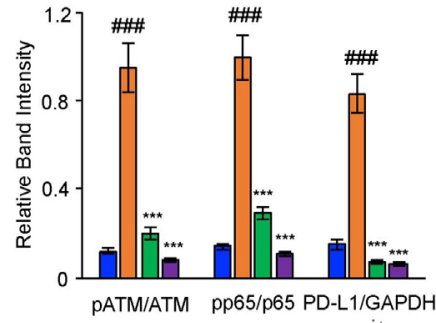

$\mathrm{H}$

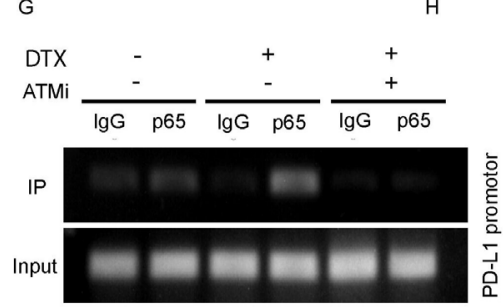

$E$

B

$$
\text { 递 }
$$
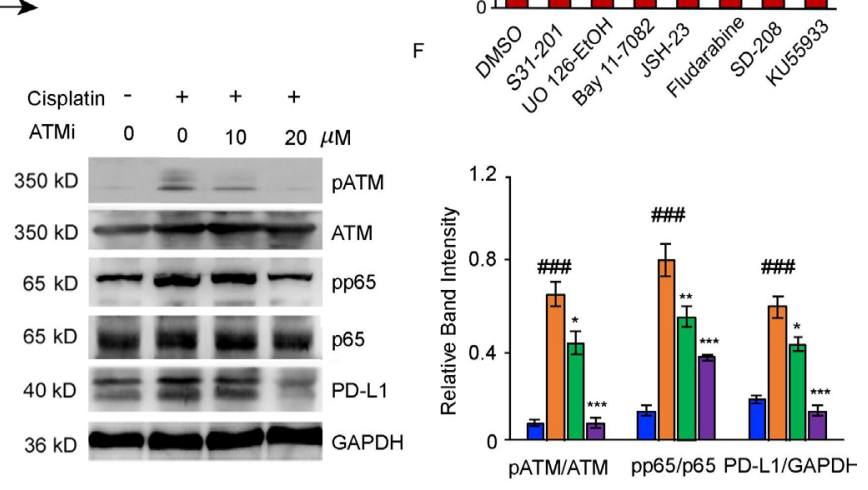

।

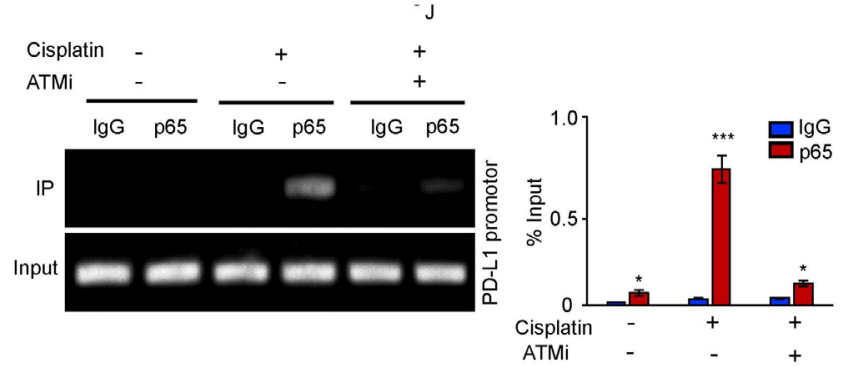

Figure 3 NF- $k B$ activity is required for the upregulation of PD-L1 in PC-3 cells after DTX treatment. (A, B) PC-3 cells were treated with $50 \mathrm{nM}$ DTX following treatment with different pathway inhibitors S31-201, U0126-EtOH, Bay11-7082, JSH-23, SD-208, fludarabine, KU55933 or a vehicle. (A) PD-L1 expression was detected by surface staining with FITC-PD-L1 antibody, followed by FACS with isotype IgG as the control. representative results of FACS from three experiments are shown in (A) and with quantifications in (B), data are shown as mean $\pm S E M$. ${ }^{*} P<0.05$; ${ }^{* \star *} \mathrm{p}<0.001$; n.s., non-significance; compared with DMSO group. (C, D) PC-3 cells were treated with $50 \mathrm{nM}$ DTX following treatment with ATM inhibitor for indicated concentrations. (C) Representative blotting for pATM, ATM, pp65, p65, and PD-L1 expression. The results from four experiments were quantified in (D). (E, F) PC-3 cells were treated with $20 \mu \mathrm{M}$ cisplatin following treatment with ATM inhibitor for indicated concentrations. (E) Representative blotting was determined by Western blotting. The results from three experiments were quantified in (F). Data are shown as mean \pm SEM. \#\#\#P<0.001, compared with non-treated group. ${ }^{*} P<0.05,{ }^{* *} p<0.01,{ }^{* *} \mathrm{p}<0.001$; compared with chemotherapy treated group. (G-J) CHIP assay. (G, H) CHIP assays with p65 antibody were performed in the PC-3 cells which treated with $50 \mathrm{nM}$ DTX following treatment with $20 \mu \mathrm{M}$ ATM inhibitor with an IgG isotype as a control. Bindings of p65 to PD$L 1$ gene promoters were quantified with the ratio of IP/input in $(\mathrm{H})$. The results from three experiments. (I-J) CHIP assays with p65 antibody were performed in the PC-3 cells which treated with $20 \mu \mathrm{M}$ cisplatin following treatment with $20 \mu \mathrm{M}$ ATM inhibitor. bindings of p65 to $P D-L 1$ gene promoters were quantified in (J) from three experiments. data are shown as mean \pm SEM. ${ }^{*} \mathrm{P}<0.05,{ }^{* \star *} \mathrm{p}<0.001$, compared with IgG groups. ATM, ataxia telangiectasia mutation; chlP, chromatin immunoprecipitation; DTX, docetaxel; PD-L1, programmed cell death ligand-1; SEM, SE of the mean.

DTX or cisplatin. Then, the PD-L1 expressions were quantified by FACS. It was demonstrated that both $50 \mu \mathrm{M}$ and $100 \mu \mathrm{M}$ of NBD effectively block PD-L1 expression mediated by DTX (figure $4 \mathrm{~A}-\mathrm{D}$ ) and cisplatin (figure $4 \mathrm{E}-\mathrm{H}$ ). The association of PD-L1 expression with NEMO mediated NF- $\mathrm{KB}$ activation was also confirmed by subjecting PD-L1 and pp65 to dual-color immunofluorescence after combined with NBD. We observed that DTX significantly induced pp65 positive staining in the nuclei of PC-3 cells. The intensity of pp65 in the cell nuclei was found to increase with the enhancement of the PD-L1 signal which is 1.6-fold higher for DTX than cisplatin treatment, and the NBD had attenuated the accumulation of pp65 in the nuclei concomitant with the downregulation of PD-L1 (figure 4I-L). The results of chIP assay showed that a markedly higher amount of chromosomal DNA containing the $P D-L 1$ promoter was immunoprecipitated with the anti-p65 antibody compared with the control IgG after the DTX or cisplatin treatment. NBD strongly attenuated the binding of p65 to the $P D-L 1$ promoter region which induced by both DTX or cisplatin (figure 4M-P). This finding supported the existence of a direct association between the PD-L1 expression and NEMO mediated p65 nuclear translocation. 


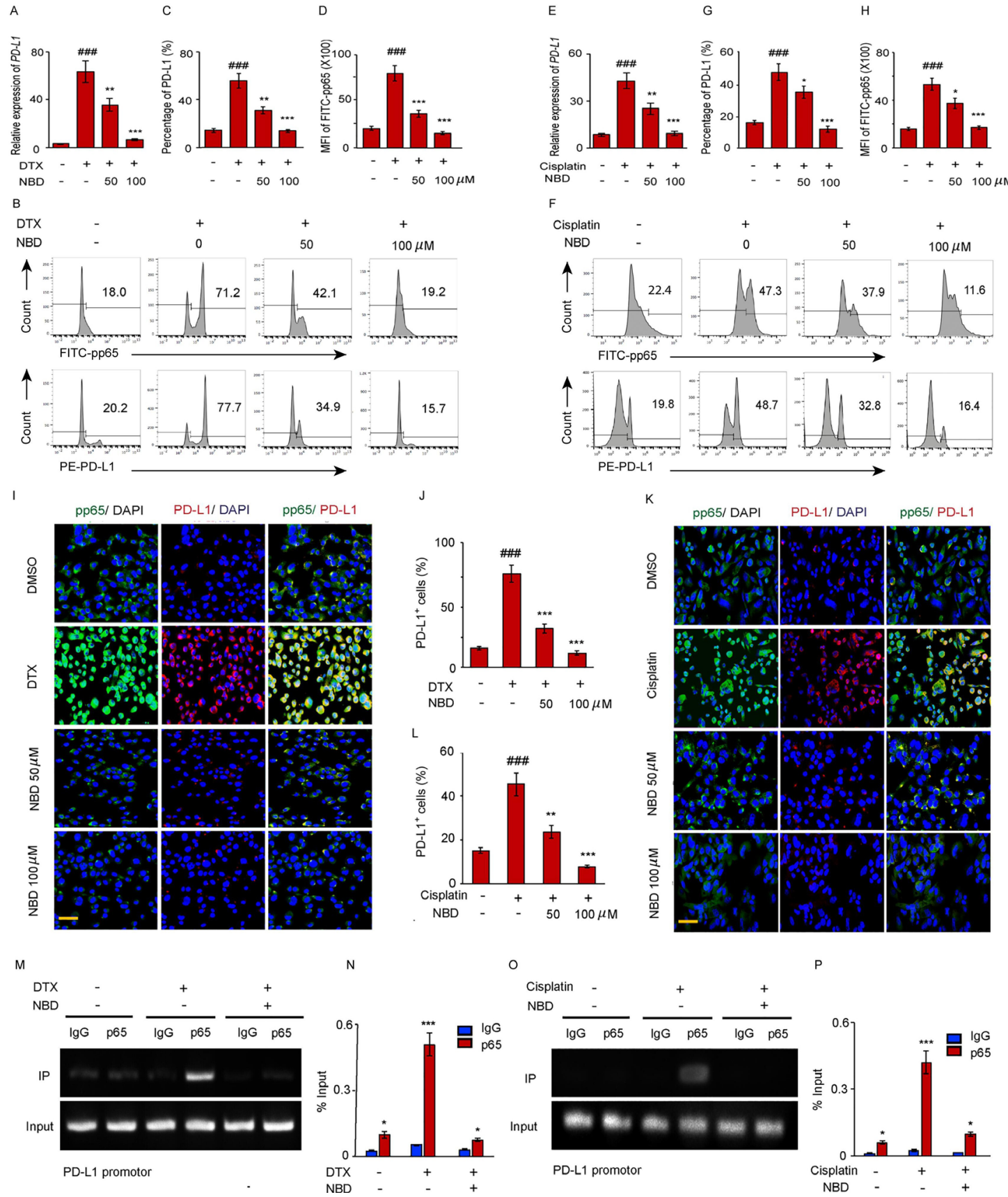

Figure 4 The small NEMO blocking peptide (NBD) blocks PD-L1 expression induced by DTX. (A-D) PC-3 cells were exposed to $50 \mathrm{nM}$ DTX following treatment with indicated doses of NBD. (A) PD-L1 gene expression after DTX treatment was quantified by qPCR. (B) PD-L1 and pp65 expressions were detected by FACS. (C) Percentage of PD-L1 positive cells were quantified from three experiments. (D) MFI of FITC-pp65 was quantified from three experiments. (E-H) PC-3 cells were exposed to $20 \mu \mathrm{M}$ cisplatin with indicated doses of NBD. (E) PD-L1 gene expression was quantified by qPCR. (F) PD-L1 and pp65 expressions were detected by FACS. (G) Percentage of PD-L1 positive cells were quantified from three experiments. (H) MFI of FITC-pp65 was quantified from three experiments. (I, J) Co-immunostaining of pp65 (green) and PD-L1 (red) in the PC-3 cells after DTX and NBD treatment. (I) Representative images are from one of three sections from indicate treated groups. Scale bar, $20 \mu \mathrm{m}$. (J) Quantification of PD-L1 positive cells from three experiments. (K, L) Co-immunostaining of pp65 (green) and PD-L1 (red) in the PC-3 cells after cisplatin and NBD treatment. (K) Representative images are from one of three sections from indicate treated groups. Scale bar, $20 \mu \mathrm{m}$. (L) Quantification of PD-L1 positive cells from three experiments. \#\#\#P<0.001, compared with those of the non-treated group; ${ }^{*} \mathrm{p}<0.05,{ }^{* *} \mathrm{p}<0.01,{ }^{* * *} \mathrm{p}<0.001$ compared with the chemotherapy only group. (M-P) CHIP assay. (M, N) CHIP assays with p65 antibody were performed in the PC-3 cells which treated with $50 \mathrm{nM}$ DTX following treatment with $100 \mu \mathrm{M}$ NBD. Bindings of 065 to $P D-L 1$ gene promoters were quantified in $(N)$. $(\mathrm{O}, \mathrm{P}) \mathrm{CHIP}$ assays with p65 antibody were performed in the PC-3 cells which treated with $20 \mu \mathrm{M}$ cisplatin and $100 \mu \mathrm{M}$ NBD. The results from three experiments were quantified in (P). All data are shown as the mean \pm SEM. ${ }^{*} \mathrm{P}<0.05,{ }^{* * *} \mathrm{p}<001$ compared with the IgG groups. CHIP, chromatin immunoprecipitation; DTX, docetaxel; FACS, fluorescent-activated cell sorting; NEMO, NF- $\mathrm{KB}$ essential modulator; PD-L1, programmed cell death ligand-1; GPCR, quantitative PCR; SEM, SE of the mean. 


\section{ATM regulated PD-L1 expression through association with NEMO}

It has been reported that DNA damage inducing stress responses increased the ATM activation and binding to NEMO in the nuclei and a further study indicated that this mechanism also works with other cell toxic stress even without DNA damage. ${ }^{40}$ To further confirm that the interaction between ATM and NEMO is a critical event involved in the activation of PD-L1 in response to DTX, we performed co-immunoprecipitation (co-IP) experiment. Reciprocal co-IP, with anti-ATM, followed by immunoblotting with anti-NEMO or co-IP with antiNEMO and immunoblotting with anti-ATM, showed enhanced stress-induced ATM-NEMO colocalization in the tumor cells after DTX (figure 5A,B) or cisplatin treatment (figure 5C,D). To confirm that NEMO and ATM interaction is dependent on the phosphorylation of ATM, PC-3 cells were treated with DTX plus KU55933 (figure 5E,F) or cisplatin plus KU55933 (figure 5G,H). The results of reciprocal co-IP showed that the binding of ATM to NEMO had decreased substantially in response to increase concentration of the ATM inhibitor, suggesting

Figure 5

A

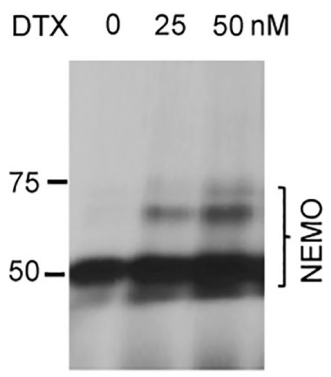

IP : anti-ATM WB: anti-NEMO
B

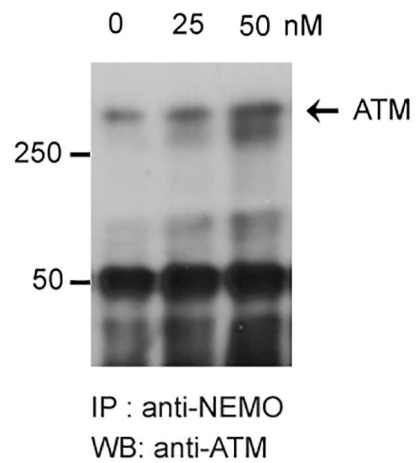

$\mathrm{F}$

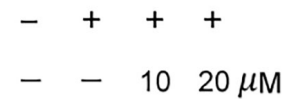

C

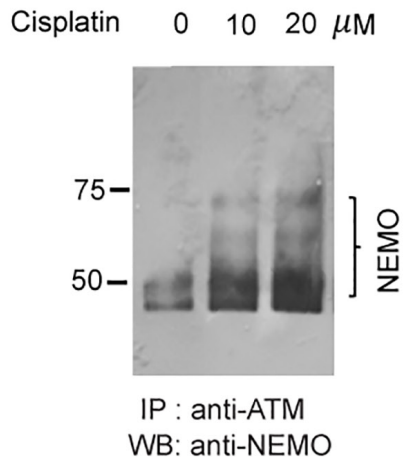

WB: anti-NEMO
D

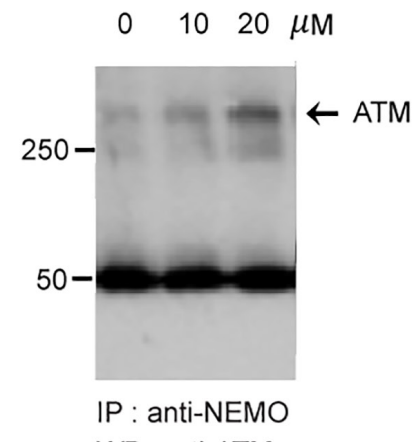

WB: anti-ATM

E

$$
\begin{aligned}
& \text { DTX }-+++ \\
& \text { ATMi }-\quad+1020 \mu \mathrm{M}
\end{aligned}
$$

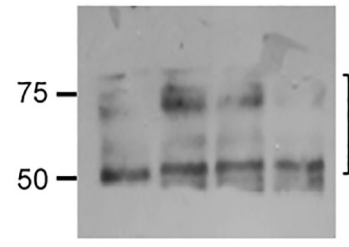

IP : anti-ATM

WB: anti-NEMO

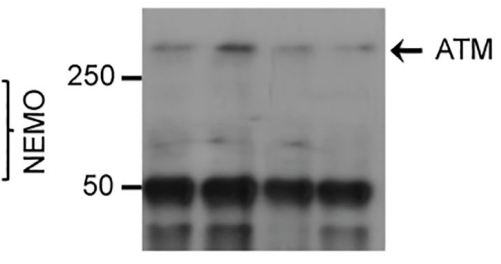

IP : anti-NEMO WB: anti-ATM
G

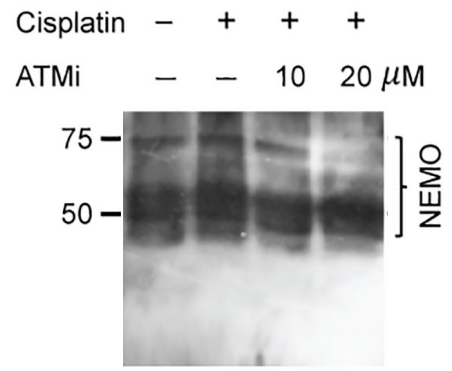

IP : anti-ATM

WB: anti-NEMO

Figure 5 ATM regulates PD-L1 expression by interacting with NEMO. (A, B) PC-3 cells were treated with DTX (0 nM, 25 nM, $50 \mathrm{nM}$ ) for 6 hours. (A) Association between DTX-induced ATM and NEMO was determined by the coimmunoprecipitation assay with anti-ATM (a mouse monoclonal lgG) followed by immunoblotting with anti-NEMO (a goat polyclonal antibody), and (B) anti-NEMO (a goat polyclonal lgG) followed by immunoblotting with anti-ATM (a mouse monoclonal antibody). Representative blots from three experiments are shown. (C, D) PC-3 cells were treated with cisplatin $(0 \mu \mathrm{M}, 10 \mu \mathrm{M}, 20 \mu \mathrm{M})$ for $24 \mathrm{hours}$. (C) Association between ATM and NEMO was determined by the coimmunoprecipitation assay with anti-ATM, followed by immunoblotting with anti-NEMO and (D) anti-NEMO, followed by immunoblotting with anti-ATM. Representative blots from three experiments are shown. (E, F) PC-3 cells were treated with $50 \mathrm{nM}$ DTX followed by ATM inhibitors or vehicle for 6 hours (E) Association between ATM and NEMO was determined by the coimmunoprecipitation assay with anti-ATM, followed by immunoblotting with anti-NEMO, and (F) anti-NEMO followed by immunoblotting with anti-ATM. Representative blots from three experiments are shown. (G, H) PC-3 cells were treated with $20 \mu \mathrm{M}$ cisplatin, followed by ATM inhibitors or vehicle for 24 hours. (G) Association between ATM and NEMO was determined by the co-immunoprecipitation assay with anti-ATM followed by immunoblotting with anti-NEMO, and $(\mathrm{H})$ anti-NEMO followed by immunoblotting with anti-ATM. Representative blots from three experiments are shown. ATM, ataxia telangiectasia mutation; DTX, docetaxel; NEMO, NF-kB essential modulator; PD-L1, programmed cell death ligand-1. 
that the interaction between NEMO and ATM depends on ATM kinase activity.

Moreover, we found that oxidative, ethanol and electric treatments which enhanced NF-KB signaling through NEMO SUMOylation also upregulated PD-L1 expression in PC-3 cells, suggesting the key role of SUMOylation of NEMO in regulating PD-L1 signaling (online supplemental figure 8).

\section{DTX with either NEMO or ATM inhibitor restricted tumor growth in vivo}

To determine whether inhibition of the ATM or NEMO could enhance the antitumor efficacy of DTX in vivo, RM-1 prostate cancer cells were injected into mice, which were subsequently treated with DTX, DTX plus KU55933, and DTX plus NBD separately, while DTX plus an antiPD-L1 blockade was used as the therapeutic control. Although DTX alone attenuated the tumor growth, its antitumor efficacy was dramatically enhanced in combination with NBD or KU55933, which was as effective as anti-PD-L1 antibody, as indicated by the decreased tumor inhibitory rate $(40.3 \%$ DTX vs. $62.8 \% \mathrm{NBD}+\mathrm{DTX}$, 74.9\% KU55933+DTX, 58.2\% anti-PD-L1+DTX, p<0.001) (figure 6A-D). Furthermore, there was no significant difference in the antitumor effect of DTX combined with NBD or KU55933 and DTX alone when T cell function was blocked, suggesting that ATM and NEMO inhibition enhanced the antitumor effect of DTX mainly through T cells.

Mechanistic studies have indicated that DTX dramatically upregulated the expression of PD-L1. KU55933 and NBD blocked the DTX-induced PD-L1 upregulation (figure 6E,F), while dual color of tumor sections staining showed a substantial increase in the number of PD-L1 ${ }^{+}$ cells with a strong pp65 signal in the nuclei of the DTXtreated sections, which was significantly reduced in the cells which treated with DTX in combination with NBD or KU55933 (figure 6G,H).

Moreover, an FACS analysis indicated that the combination of NBD or KU55933 could dramatically increase the $\mathrm{T}$ cell percentage both in circulation and tumors (figure 6I). Compared with the DTX-only group, DTX plus NBD or KU55933 significantly increased the ratio of $\mathrm{CD}^{+} \mathrm{IFN} \gamma^{+}$effector $\mathrm{T}$ cells and decreased the ratio of $\mathrm{CD}^{+} \mathrm{CD} 25^{+} \mathrm{FOXP}^{+}$regulatory $\mathrm{T}$ cells in the tumor (figure 6J,K). The immunotherapeutic effects of the KU55933 and NBD were comparable with the effects of anti-PD-L1 blockade. In addition, the combination of DTX with NBD or KU55933 increased the proliferation capacity of $\mathrm{CD}^{+} \mathrm{T}$ cells with a remarkable increase in the number of $\mathrm{CD} 8^{+} \mathrm{KI}_{67^{+}} \mathrm{T}$ cells compared with DTX alone (figure 6L,M), suggesting that the inhibition of NEMO and ATM blocked the PD-L1-induced immunosuppression in prostate tumor, which was associated with exposure to DTX. Moreover, we did not observe any significant $\mathrm{T}$ cell activation in the groups combined with CD3 blockade antibody, supporting the notion that the antitumor effect of NEMO and ATM inhibitors depends on $\mathrm{T}$ cells.

To further confirm that pharmacological inhibition of NEMO and ATM enhances the antitumor efficacy of DTX, a chimeric mouse was created using PC-3 cells and PBMCs of patients (online supplemental figure 9A-H). Similar to the aforementioned results, the combination of NBD or KU55933 with DTX substantially increased the tumor inhibitory rate, while no therapeutic benefit of the combination treatment was observed in the $\mathrm{T}$ cell depletion groups (Online supplemental figure 9I-L). Furthermore, KU55933 and NBD attenuated the DTXinduced PD-L1 upregulation (online supplemental figure $9 \mathrm{M}-\mathrm{P})$. An immunohistochemically analysis of the $\mathrm{CD}^{+}$ $\mathrm{T}$ cells in the tumor sections indicated that the inhibitors could dramatically increase the $\mathrm{T}$ cell tumor-infiltration and percentage of $\mathrm{CD}^{+}{ }^{+} \mathrm{IFN} \gamma^{+}$effector T cells compared with that of DTX (online supplemental figure 9Q,R). Notably, the proliferation capacity of $\mathrm{CD}^{+} \mathrm{T}$ cells was also increased in the combination treatment groups (online supplemental figure 9S,T), confirming that the inhibition of NEMO and ATM plus DTX resulted in a significantly greater antitumor response than that by DTX alone.

\section{DISCUSSION}

In this study, we showed that upregulation of PD-L1 expression contributed to the development of drug resistance for DTX. Moreover, we identified a new immunosuppressive and tumor promoting function of activated ATM combined with NEMO in response to DTX chemotherapy. We demonstrated that NEMO specifically binds to ATM and activates NF-KB, which is essential for PD-L1 expression in prostate cancer cells after DTX treatment.

DTX, which promotes microtubule stabilization, thus ensuring that cancer cells remain in the G2/M phase, is the first-line treatment for the advanced mPCa. ${ }^{11-13}$ However, DTX-resistance is a major cause of disease recurrence and progression. The interaction between PD-1 and PD-L1 leads to immune escape, which is one of the most important mechanisms of tumor resistance. In this study, we demonstrated that PD-L1 expression in prostate cancer cells was significantly upregulated by DTX. ATM kinase is critical for the regulation of the cell cycle checkpoint. An important assumption of this study is possible activation of ATM kinase by DTX treatment, which attenuates cells during the G2/M phase.

The classical activator for ATM is DNA damage. Recently, studies have suggested that PD-L1 expression is significantly upregulated by ATM mediated DDR signaling. ${ }^{22-24} 41$ Here, we observed the strong increase in the PD-L1 expression after the cisplatin treatments in prostate cancer cells and noted that ATM largely contributed to the upregulation of the PD-L1 expression in cancer cells in response to cisplatin. Further mechanistic studies have indicated that activated ATM associate with NEMO, which subsequently activates NF- $\mathrm{KB}$, is required for ATM mediated PD-L1 


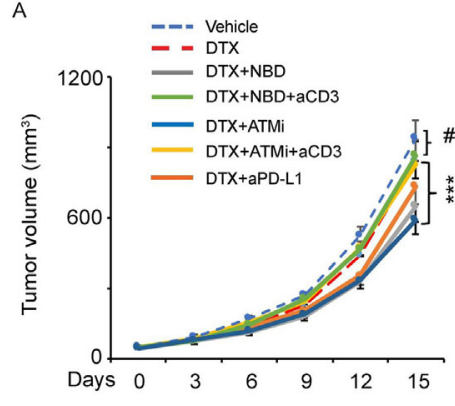

E

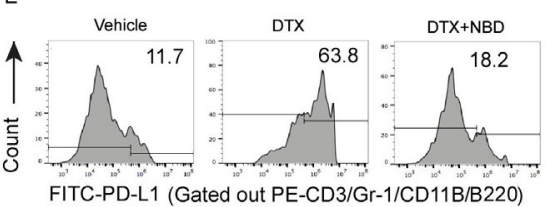

FITC-PD-L1 (Gated out PE-CD3/Gr-1/CD11B/B220)

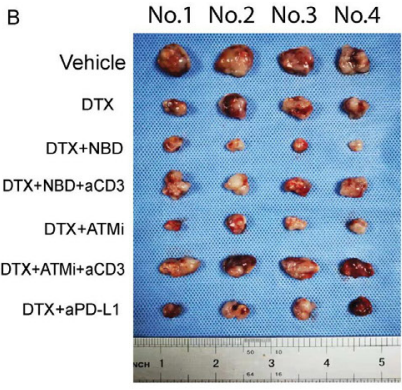

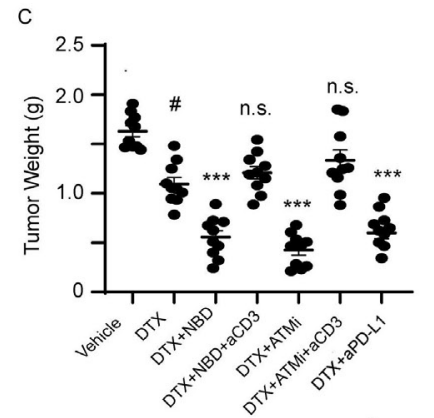

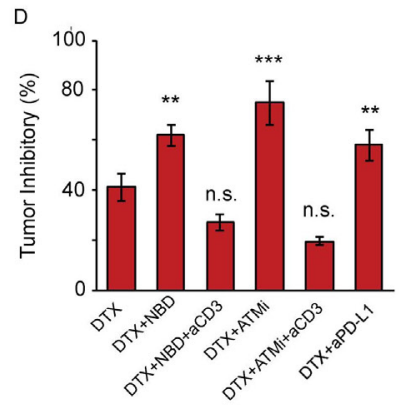

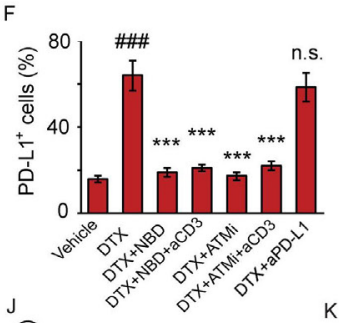
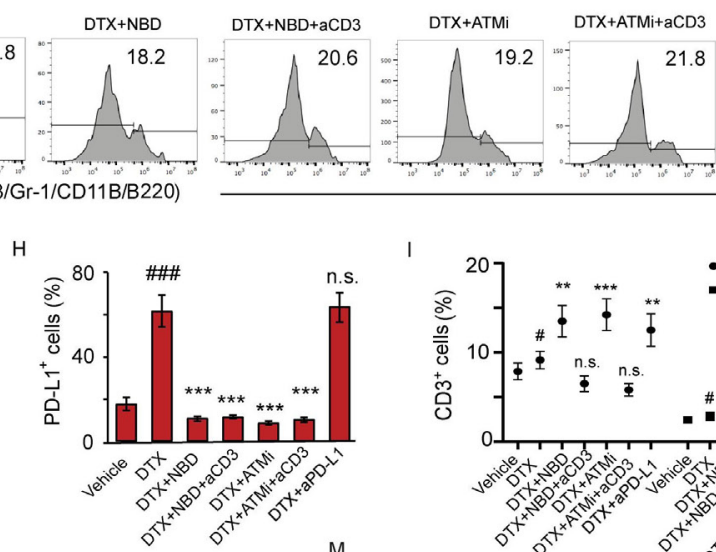

DTX+aPD-L1

G

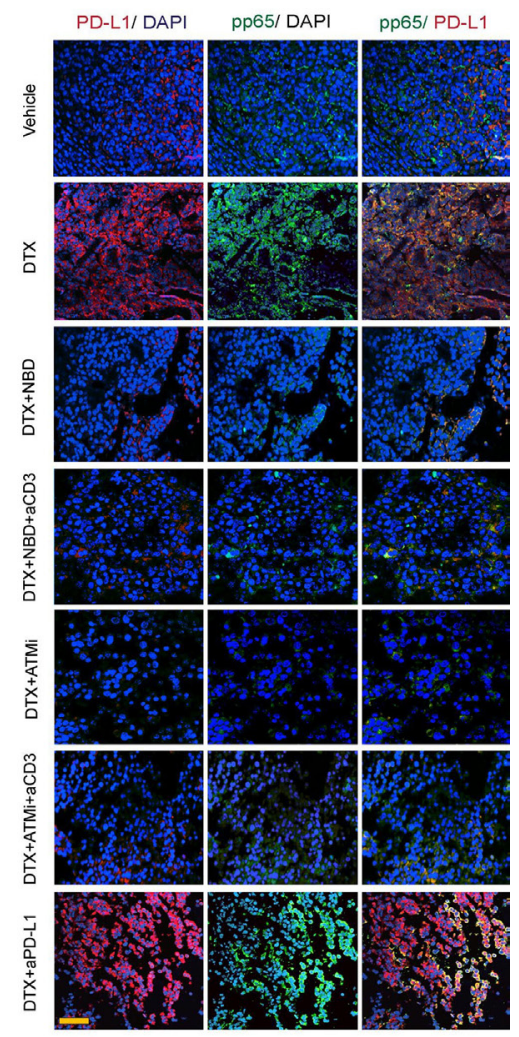

FITC-KI67

Figure 6 ATM and NEMO inhibitors promote the antitumor effect of DTX through downregulation of PD-L1. C57BL/6 mice implanted with RM-1 prostate tumors were divided to 7 groups with 10 mice per group and treated with (1) vehicle, (2) DTX, (3) NBD plus DTX, (4) NBD plus DTX and anti-CD3, (5) KU55933 plus DTX, (6) KU55933 plus DTX and anti-CD3, and (7) anti-PD-L1 plus DTX as a therapeutic control group. (A-D) ATM and NEMO inhibitors promote the antitumor effect of DTX. (A) Tumor volumes were measured at the indicated day after treatment. ANOVA, $\# \mathrm{p}<0.05$, compared with vehicle group; ${ }^{\star \star \star} \mathrm{p}<0.001$, compared with DTX only group. (B) Photo of tumors in individual groups. (C) Mean tumor weight $\pm S E M$. (D) Mean tumor inhibitory rate \pm SEM. (E-M) ATM and NBD inhibitors attenuate DTX-induced PD-L1 expression in prostate tumors. (E-H) Representative histograms of PD-L1 expression on cancer cells for the designated treatments with quantifications in (F). The results from three experiments. (G, H) Co-immunostaining of pp65 (green) and PD-L1 (red) in the implanted tumor sections. (G) Representative images are from one of three sections from the vehicle $(n=10)$ and indicate treated groups $(n=10)$. Scale bar, $20 \mu \mathrm{m}$. (H) Quantifications of PD-L1 positive cells in the sections from indicated treatments. (I-K) Effector function of tumorinfiltrating T cells. (I) $\mathrm{CD}^{+} \mathrm{T}$ cells distribution in total PBMCs and tumor tissue. (J) Ratio of $\mathrm{CD}^{+} \mathrm{IFN}-\gamma^{+} \mathrm{T}$ cells in total $\mathrm{CD}^{+} \mathrm{T}$ cells in tumor tissue. (K) Ratio of $\mathrm{CD}^{+} \mathrm{CD}^{+} 5^{+} \mathrm{FOXP3}^{+}$regulatory T cells in total $\mathrm{CD}^{+} \mathrm{T}$ cells in tumor tissue. (L, M) The CD8 T cells were first gated with APC-CD8 antibody, and then the KI67 expression was analyzed in CD8 ${ }^{+}$population with FITCKI67 antibody. (L) Representative contour plots by FACS depicting KI67 $7^{+}$expression on tumor-infiltrating $\mathrm{CD} 8^{+} \mathrm{T}$ cells. (M) Quantitation of the percentages of $\mathrm{CD} 8^{+} \mathrm{T}$ cells and the percentages of proliferating $\mathrm{CD} 88^{+} \mathrm{KI} 67^{+} \mathrm{T}$ cells in tumor. All data are shown as the mean \pm SEM. \#P<0.05, \#\#\#p<0.001, compared with vehicle group; ${ }^{* \star} p<0.01,{ }^{\star \star \star} p<0.001$, compared with $\mathrm{DTX}$ only group. ANOVA, analysis of variance; DTX, docetaxel; IFN- $\gamma$, interferon- $\gamma$, NEMO, NF-kB essential modulator; n.s., nonsignificance; PBMCs, peripheral blood mononuclear cells; PD-L1, SEM, SE of the mean.

expression. ${ }^{4042} 43$ Therefore, our study has first identified a previously uncharacterized role of ATM-NEMO signaling in promoting PD-L1 transcription following chemotherapeutics. 
One of the key mechanistic questions was whether the dual signal initiation model of ATM-NEMO for the PD-L1 upregulation was relevant to the PD-L1 upregulation following DTX chemotherapy in prostate cancer, which does not induce obvious DNA damage signaling. Indeed, we found that chemotherapeutic treatment with DTX caused a 2-fold higher of PD-L1 induction than cisplatin with a considerably lower dose in prostate cancer cells. Consistently, this activation involved both ATM activation and ATM-NEMO binding. Moreover, both ATM and NEMO function inhibition can blunt the PD-L1 in prostate cancer cells induced by DTX. These results revealed a novel mechanism of DTX resistance by the upregulation of PD-L1.

Our findings are clinically significant and highly relevant for the treatment of cancers that lack PD-L1 expression, such as prostate cancer. Recent reports on the PD-1/PD-L1 immunotherapy for prostate cancer are relatively disappointing. ${ }^{44}$ However, we have observed an increased PD-L1 expression after DTX treatment, which correlated with tumor progression in the mouse bearing the prostate tumor. The combination of DTX with the pharmacological inhibition of ATM or NBD attenuated DTX-induced PD-L1 upregulation, which had synergistically enhanced the anti-tumor efficacy of DTX. ${ }^{46}$ Mechanistically, DTX dramatically promoted the nuclear translocation of NF- $\mathrm{KB}$ p65 and induced PD-L1 expression. ATM phosphorylates NEMO, which results in NEMO SUMOylation, is a key step for NF- $\mathrm{KB}$ p65 nuclear translocation. We observed that a dose-dependent increasing of ATM-NEMO association after DTX treatment. Therefore, the NF-kB-PD-L1 axis was activated by DTX through promoting ATM-NEMO binding. ATM inhibition effectively interrupted ATM interaction with NEMO and NBD specifically blocked NEMO activation. Thus, the inhibition of NEMO and ATM along with DTX resulted in a significantly greater antitumor response than that of DTX alone.

The question was raised how ATM-NEMO mediates PD-L1 expression, which can be related to the enhanced immunosuppression following DTX chemotherapy. It has been reported that PD-1 is upregulated on the tumorinfiltrating $\mathrm{T}$ cells in the tumor microenvironment of prostate cancer, ${ }^{47}$ which characterized by lacking the expression of perforin and IFN- $\gamma^{48-50}$ We found that suppressing the PD-L1 expression by inhibiting NEMO and ATM increased the number of circulating and tumor-infiltrating T cells in both RM-1 and PC-3 tumorbearing mice. Specifically, an increase percentage of the IFN- $\gamma$ positive cytotoxic T cells and decrease of the regulatory $\mathrm{T}$ cells contribute to the reverse of the immunosuppressive state of tumor. Furthermore, an increase in the proliferation capacity of CD8 $\mathrm{T}$ cells may also play an important role in the enhancing of the antitumor effect of DTX.

\section{CONCLUSION}

Our study identified a previously uncharacterized type of ATM-NEMO signaling induced by DTX capable of suppressing the tumor immunity by activating PD-L1 expression. The present findings indicated that combination treatment with DTX and NEMO or ATM inhibitors can be exploited to develop a new therapeutic strategy to overcome cancer immune tolerance associated with the use of DTX, providing an alternative to PD-L1 antibodies as a means of restoring cancer immunity. This might be of great benefit for patients resistant to antibody therapy.

Acknowledgements We thank all patients and medical staff who generously contributed to this study. All authors have read and approved the final submitted version of the manuscript.

Contributors All authors were involved in drafting the article or revising it critically for important intellectual content. Study conception and design: ZW, XZ, WL, LC and LS. Acquisition of data: ZW, XZ, WL, QS, ZYH, XZ, HC, CM, BH, WO, JC and GZ. Analysis and interpretation of data: ZW, XZ, WL, LC and LS.

Funding This work was supported by the National Natural Science Foundation of China (grant no. 81901849 and 82071818), the Guangdong Natural Science Foundation (grant no. 2018A030310328 and 2021A1515011030), Medical Scientific Research Foundation of Guangdong Province, China (grant no. A2018344).

Competing interests No, there are no competing interests.

\section{Patient consent for publication Not required.}

Ethics approval The ethical approval was authorized by the Institutional Review Board of the First Affiliated Hospital of Sun Yat-sen University, and written consent was obtained from all patients included.

Provenance and peer review Not commissioned; externally peer reviewed.

Data availability statement Data are available on reasonable request. The datasets used and/or analyzed during the current study are available from the corresponding author on reasonable request.

Supplemental material This content has been supplied by the author(s). It has not been vetted by BMJ Publishing Group Limited (BMJ) and may not have been peer-reviewed. Any opinions or recommendations discussed are solely those of the author(s) and are not endorsed by BMJ. BMJ disclaims all liability and responsibility arising from any reliance placed on the content. Where the content includes any translated material, BMJ does not warrant the accuracy and reliability of the translations (including but not limited to local regulations, clinical guidelines, terminology, drug names and drug dosages), and is not responsible for any error and/or omissions arising from translation and adaptation or otherwise.

Open access This is an open access article distributed in accordance with the Creative Commons Attribution Non Commercial (CC BY-NC 4.0) license, which permits others to distribute, remix, adapt, build upon this work non-commercially, and license their derivative works on different terms, provided the original work is properly cited, appropriate credit is given, any changes made indicated, and the use is non-commercial. See http://creativecommons.org/licenses/by-nc/4.0/.

\section{ORCID iD}

Lan Shao http://orcid.org/0000-0001-6725-4433

\section{REFERENCES}

1 Weber JS, Kudchadkar RR, Yu B, et al. Safety, efficacy, and biomarkers of nivolumab with vaccine in ipilimumab-refractory or -naive melanoma. J Clin Oncol 2013;31:4311-8.

2 Garon EB, Rizvi NA, Hui R, et al. Pembrolizumab for the treatment of non-small-cell lung cancer. N Engl J Med 2015;372:2018-28.

3 Zou W, Wolchok JD, Chen L. Pd-L1 (B7-H1) and PD-1 pathway blockade for cancer therapy: mechanisms, response biomarkers, and combinations. Sci Transl Med 2016;8:328rv4.

4 Thoma C. Prostate cancer: PD-L1 expression is common and indicates poor prognosis. Nat Rev Urol 2016;13:5.

5 Gevensleben H, Dietrich D, Golletz C, et al. The immune checkpoint regulator PD-L1 is highly expressed in aggressive primary prostate cancer. Clin Cancer Res 2016;22:1969-77. 
6 Massari F, Ciccarese C, Caliò A, et al. Magnitude of PD-1, PD-L1 and $\mathrm{T}$ lymphocyte expression on tissue from castration-resistant prostate adenocarcinoma: an exploratory analysis. Target Oncol 2016;11:345-51.

7 Schepisi G, Farolfi A, Conteduca V, et al. Immunotherapy for prostate cancer: where we are headed. Int J Mol Sci 2017;18:2627.

8 Papanicolau-Sengos A, Yang Y, Pabla S, et al. Identification of targets for prostate cancer immunotherapy. Prostate 2019;79:498-505.

9 Barata P, Agarwal N, Nussenzveig R, Gerendash B, et al. Clinical activity of pembrolizumab in metastatic prostate cancer with microsatellite instability high $(\mathrm{MSI}-\mathrm{H})$ detected by circulating tumor DNA. J Immunother Cancer 2020;8:e001065.

10 Martin AM, Nirschl TR, Nirschl CJ, et al. Paucity of PD-L1 expression in prostate cancer: innate and adaptive immune resistance. Prostate Cancer Prostatic Dis 2015;18:325-32.

11 Messina C, Messina M, Boccardo F. Abiraterone or docetaxel for Castration-sensitive metastatic prostate cancer? that is the question Eur Urol 2018;73:147-8.

12 Tucci M, Bertaglia V, Vignani F, et al. Addition of docetaxel to androgen deprivation therapy for patients with hormone-sensitive metastatic prostate cancer: a systematic review and meta-analysis. Eur Urol 2016;69:563-73.

13 Tsao C-K, Galsky MD, Oh WK. Docetaxel for metastatic hormonesensitive prostate cancer: urgent need to minimize the risk of neutropenic fever. Eur Urol 2016;70:707-8.

14 Tannock IF, de Wit R, Berry WR, et al. Docetaxel plus prednisone or mitoxantrone plus prednisone for advanced prostate cancer. $N$ Engl J Med 2004;351:1502-12.

15 Nuhn P, De Bono JS, Fizazi K, et al. Update on systemic prostate cancer therapies: management of metastatic castration-resistant prostate cancer in the era of precision oncology. Eur Urol 2019;75:88-99.

16 Leduc C, Adam J, Louvet E, et al. Tpf induction chemotherapy increases PD-L1 expression in tumour cells and immune cells in head and neck squamous cell carcinoma. ESMO Open 2018;3:e000257.

17 Francini E, Sweeney CJ. Docetaxel activity in the era of Lifeprolonging hormonal therapies for metastatic castration-resistant prostate cancer. Eur Urol 2016;70:410-2.

18 Conteduca V, Jayaram A, Romero-Laorden N, et al. Plasma androgen receptor and docetaxel for metastatic castration-resistant prostate cancer. Eur Urol 2019;75:368-73.

19 Fernández-García EM, Vera-Badillo FE, Perez-Valderrama B, et al. Immunotherapy in prostate cancer: review of the current evidence. Clin Transl Oncol 2015;17:339-57.

20 Yang Z, Shen Y, Oishi H, et al. Restoring oxidant signaling suppresses proarthritogenic $T$ cell effector functions in rheumatoid arthritis. Sci Transl Med 2016;8:331ra38.

21 Oricchio E, Saladino C, lacovelli S, et al. ATM is activated by default in mitosis, localizes at centrosomes and monitors mitotic spindle integrity. Cell Cycle 2006;5:88-92.

22 Zhu Z, Chen P, Yan Z. DNA damage response signaling as a predictive biomarker and synergistic therapeutic target for anti-PD-1/ PD-L1 immunotherapy in non-small cell lung cancer. Thorac Cancer 2018;9:901-3.

23 Teo MY, Seier K, Ostrovnaya I, et al. Alterations in DNA damage response and repair genes as potential marker of clinical benefit from PD-1/PD-L1 blockade in advanced urothelial cancers. J Clin Oncol 2018;36:1685-94.

24 Sun L-L, Yang R-Y, Li C-W, et al. Inhibition of ATR downregulates PD$\mathrm{L} 1$ and sensitizes tumor cells to T cell-mediated killing. Am J Cancer Res 2018;8:1307-16.

25 Sato H, Niimi A, Yasuhara T, et al. DNA double-strand break repair pathway regulates PD-L1 expression in cancer cells. Nat Commun 2017:8:1751

26 Jin X, Ding D, Yan Y, et al. Phosphorylated RB promotes cancer immunity by inhibiting NF- $\mathrm{KB}$ activation and PD-L1 expression. Mol Cell 2019;73:22-35.

27 Miyamoto S. Nuclear initiated NF- $\kappa$ B signaling: NEMO and ATM take center stage. Cell Res 2011;21:116-30.
28 Wu Z-H, Wong ET, Shi Y, et al. Atm- and NEMO-dependent ELKS ubiquitination coordinates TAK1-mediated IKK activation in response to genotoxic stress. Mol Cell 2010;40:75-86.

29 McCool KW, Miyamoto S. Dna damage-dependent NF- $\kappa B$ activation: NEMO turns nuclear signaling inside out. Immunol Rev 2012;246:311-26.

30 Shao L, Fujii H, Colmegna I, et al. Deficiency of the DNA repair enzyme ATM in rheumatoid arthritis. J Exp Med 2009;206:1435-49.

31 Shao L, Zhou HJ, Zhang H, et al. SENP1-mediated NEMO deSUMOylation in adipocytes limits inflammatory responses and type-1 diabetes progression. Nat Commun 2015;6:8917

32 Vendetti FP, Karukonda P, Clump DA, et al. Atr kinase inhibitor AZD6738 potentiates CD8+ T cell-dependent antitumor activity following radiation. J Clin Invest 2018;128:3926-40.

33 Gao Y, Nihira NT, Bu X, et al. Acetylation-Dependent regulation of PD-L1 nuclear translocation dictates the efficacy of anti-PD-1 immunotherapy. Nat Cell Biol 2020;22:1064-75.

34 Fernandez-Capetillo O, Chen H-T, Celeste A, et al. DNA damageinduced G2-M checkpoint activation by histone H2AX and 53BP1. Nat Cell Biol 2002;4:993-7.

35 Bakkenist CJ, Kastan MB. DNA damage activates ATM through intermolecular autophosphorylation and dimer dissociation. Nature 2003;421:499-506

36 Jazayeri A, Falck J, Lukas C, et al. ATM- and cell cycle-dependent regulation of ATR in response to DNA double-strand breaks. Nat Cell Biol 2006;8:37-45.

37 Poruchynsky MS, Komlodi-Pasztor E, Trostel S, et al. MicrotubuleTargeting agents augment the toxicity of DNA-damaging agents by disrupting intracellular trafficking of DNA repair proteins. Proc Natl Acad Sci U S A 2015;112:1571-6.

38 Wu Z-H, Shi Y, Tibbetts RS, et al. Molecular linkage between the kinase ATM and NF-kappaB signaling in response to genotoxic stimuli. Science 2006;311:1141-6.

39 Mabb AM, Wuerzberger-Davis SM, Miyamoto S. Piasy mediates NEMO sumoylation and NF-kappaB activation in response to genotoxic stress. Nat Cell Biol 2006;8:986-93.

40 Wuerzberger-Davis SM, Nakamura Y, Seufzer BJ, et al. Nf-kappaB activation by combinations of NEMO sumoylation and ATM activation stresses in the absence of DNA damage. Oncogene 2007;26:641-51.

41 Wang Z, Zhao J, Wang G, et al. Comutations in DNA damage response pathways serve as potential biomarkers for immune checkpoint blockade. Cancer Res 2018;78:6486-96.

42 Herbst RS, Soria J-C, Kowanetz M, et al. Predictive correlates of response to the anti-PD-L1 antibody MPDL3280A in cancer patients. Nature 2014;515:563-7.

43 Huang TT, Wuerzberger-Davis SM, Wu Z-H, et al. Sequential modification of NEMO/IKKgamma by SUMO-1 and ubiquitin mediates NF-kappaB activation by genotoxic stress. Cell 2003;115:565-76.

44 Comiskey MC, Dallos MC, Drake CG. Immunotherapy in prostate cancer: teaching an old dog new tricks. Curr Oncol Rep 2018;20:75.

45 Haffner MC, Guner G, Taheri D, et al. Comprehensive evaluation of programmed Death-Ligand 1 expression in primary and metastatic prostate cancer. Am J Pathol 2018;188:1478-85

46 Lacour M, Hiltbrunner S, Lee S-Y, et al. Adjuvant chemotherapy increases programmed Death-Ligand 1 (PD-L1) expression in nonsmall cell lung cancer recurrence. Clin Lung Cancer 2019;20:391-6.

47 Ebelt K, Babaryka G, Frankenberger B, et al. Prostate cancer lesions are surrounded by Foxp3+, PD-1+ and B7-H1+ lymphocyte clusters. Eur J Cancer 2009;45:1664-72.

48 Ebelt K, Babaryka G, Figel AM, et al. Dominance of CD4+ lymphocytic infiltrates with disturbed effector cell characteristics in the tumor microenvironment of prostate carcinoma. Prostate 2008;68:1-10.

49 Petitprez F, Fossati N, Vano Y, et al. PD-L1 expression and CD8 ${ }^{+}$Tcell infiltrate are associated with clinical progression in patients with node-positive prostate cancer. Eur Urol Focus 2019;5:192-196.

50 Barach YS, Lee JS, Zang X. T cell coinhibition in prostate cancer: new immune evasion pathways and emerging therapeutics. Trends Mol Med 2011;17:47-55. 